\title{
CRÓNICA DE JURISPRUDENCIA DEL TRIBUNAL DE JUSTICIA DE LA UNIÓN EUROPEA, ENERO-ABRIL 2017
}

\author{
FERNANDO CASTILLO DE LA TORRE
}

fernando.castillo-de-la-torre@ec.europa.eu

PETRA NEMECKOVA ${ }^{1}$

petra.Nemeckova@ec.europa.eu

I. INSTITUCIONES, PRINCIPIOS Y DERECHOS FUNDAMENTALES. II. CONTENCIOSO. III. MERCADO INTERIOR, LIBRE CIRCULACIÓN Y CIUDADANÍA EUROPEA. IV. COMPETENCIA. V. APROXIMACIÓN DE LEGISLACIONES. VI. DERECHO SOCIAL. VII. JUSTICIA, LIBERTAD Y SEGURIDAD. VIII. RELACIONES EXTERIORES.

1 Miembros del Servicio Jurídico de la Unión Europea. 


\section{INSTITUCIONES, PRINCIPIOS Y DERECHOS FUNDAMENTALES}

Una sanción del $50 \%$ del importe del impuesto sobre el valor añadido (IVA) que un sujeto pasivo está obligado a pagar a la administración tributaria, aun cuando esta última no ha sufrido una pérdida de ingresos fiscales y no existen indicios de fraude fiscal, infringe el principio de proporcionalidad (Sentencia de 26 de abril de 2017, Tibor Farkas, C-564/15, EU:C:2017:302).

Esta sentencia tenía por objeto una petición de decisión prejudicial planteada un tribunal de Hungría en la que se pedía interpretar la Directiva 2006/112/CE del Consejo, relativa al sistema común del IVA. Las autoridades tributarias húngaras constataban la existencia de una deuda tributaria a cargo del Sr. Farkas (de unos 2400 euros) y le imponían una multa tributaria por no haber aplicado las disposiciones nacionales relativas al régimen de inversión del sujeto pasivo. Aparte de cuestiones de interpretación de la directiva relativa al IVA, esta sentencia tiene un interés más fundamental por la segunda cuestión prejudicial planteada en la que se pedía al Tribunal de Justicia (TJUE) que dilucide sobre si es proporcional la sanción por la elección de un modo de tributación incorrecto en el caso de declaración de una diferencia tributaria que conlleva también la imposición de una multa tributaria del 50 $\%$ cuando no se ha producido ninguna pérdida de ingresos para la Hacienda Pública ni existen indicios de abuso.

Este asunto es un caso raro en que el TJUE consideró que, efectivamente, la sanción infringía el principio de proporcionalidad. El TJUE recordó, en un primer lugar, que a falta de armonización de la legislación de la Unión en el ámbito de las sanciones aplicables en caso de inobservancia de los requisitos fijados por un régimen establecido mediante dicha legislación, los Estados miembros son competentes para establecer las sanciones que les parezcan adecuadas. Sin embargo, están obligados a ejercer esta competencia respetando el derecho de la Unión y sus principios generales y, por consiguiente, respetando el principio de proporcionalidad, lo que significa, en otras palabras, que tales sanciones no deben ir más allá de lo necesario para alcanzar los objetivos de garantizar la correcta recaudación del impuesto y prevenir el fraude. Al objeto de apreciar si una sanción es conforme al principio de proporcionalidad, es preciso tener en cuenta, en particular, la naturaleza y la gravedad de la infracción que se penaliza con esa sanción, así como el método para la determinación de su cuantía.

Pues bien, aplicando estas premisas a la sanción impuesta al Sr. Farkas en el marco del litigio principal, el TJUE constató, siguiendo los criterios defendidos por la Comisión, que en lo atinente a la naturaleza y la gravedad 
de la infracción objeto del litigio principal se trataba de un error relativo a la aplicación del mecanismo del IVA, por lo que es de naturaleza administrativa, y que, por una parte, no causó a la administración tributaria una pérdida de ingresos y, por otra parte, se caracteriza por la inexistencia de indicios de fraude. El TJUE concluyó que en tales circunstancias, la imposición al Sr. Farkas de una sanción del $50 \%$ del importe del IVA aplicable a la operación de que se trata parece desproporcionada.

\section{CONTENCIOSO}

\section{El TJUE se considera competente para pronunciarse con carácter preju- dicial sobre la legalidad de las medidas restrictivas adoptadas en el mar- co de la PESC común respecto de particulares o entidades (Sentencia de 28 de marzo de 2017, Rosneft, C-72/15, EU:C:2017:236).}

El TJUE estaba llamado a apreciar la validez de la Decisión 2014/512/ PESC del Consejo y del Reglamento UE 833/2014 del Consejo, de la misma fecha, mediante los cuales el Consejo adoptó medidas restrictivas en respuesta a las acciones de Rusia destinadas a desestabilizar la situación de Ucrania (véase infra, sobre relaciones exteriores).

En relación con su propia competencia, el TJUE recuerda con carácter previo que, si bien con arreglo al art. 24 TUE, apdo. 1, párr. segundo, última frase, $y$ al art. 275 TFUE, párr. primero, el TJUE, en principio, no tiene competencia en relación con las disposiciones referidas a la PESC o con los actos adoptados sobre la base de estas, los Tratados instauran expresamente dos excepciones a dicho principio. En efecto, por una parte, tanto el art. 24 TUE, apdo. 1, párr. segundo, última frase, como el art. 275 TFUE, párr. segundo, establecen que el TJUE será competente para controlar el respeto del art. 40 TUE. Por otra parte, el art. 24 TUE, apdo. 1, párr. segundo, última frase, atribuye al TJUE la competencia para controlar la legalidad de determinadas decisiones contempladas en el art. 275 TFUE, párr. segundo. A su vez, esta última disposición establece que el TJUE será competente para pronunciarse sobre los recursos interpuestos en las condiciones contempladas en el art. 263 TFUE, párr. cuarto, y relativos al control de la legalidad de las decisiones adoptadas por el Consejo, sobre la base de las disposiciones relativas a la PESC, por las que se establezcan medidas restrictivas frente a personas físicas o jurídicas.

Por lo que se refiere, en primer lugar, a la competencia del TJUE para controlar el respeto del art. 40 TUE, señala que dicho control está incluido en la competencia general que el art. 19 TUE confiere al TJUE para garantizar 
el respeto del derecho en la interpretación y aplicación de los Tratados. Al establecer dicha competencia general, el art. 19 TUE, apdo. 3, letra b), indica además, entre otras cosas, que el TJUE se pronunciará con carácter prejudicial, a petición de los órganos jurisdiccionales nacionales, sobre la validez de los actos adoptados por las instituciones de la Unión. Por consiguiente, el TJUE es competente para pronunciarse sobre una petición de decisión prejudicial que se refiera a la compatibilidad de la Decisión 2014/512 con el art. 40 TUE.

En segundo lugar, examina si el TJUE es competente para pronunciarse con carácter prejudicial y realizando una apreciación de la validez de las decisiones adoptadas en materia de PESC, como es el caso de la Decisión 2014/512, cuando dichas decisiones establezcan medidas restrictivas frente a personas físicas o jurídicas. Es jurisprudencia reiterada que el control de la legalidad de los actos de la Unión garantizado en virtud de los Tratados por el TJUE se fundamenta en dos procedimientos judiciales complementarios. En efecto, el Tratado FUE, mediante sus arts. 263 y 277, por una parte, y mediante su art. 267, por otra, ha establecido un sistema completo de vías de recurso y de procedimientos destinado a garantizar el control de la legalidad de los actos de la Unión, confiando dicho control al juez de la Unión.

A este sistema completo de vías de recurso y de procedimientos le es inherente el hecho de que se confiera a los justiciables, en el marco de un recurso interpuesto ante un tribunal nacional, el derecho a cuestionar la legalidad de disposiciones incluidas en actos de la Unión que sirvan de base para la resolución o acto nacionales adoptados respecto de ellos, invocando la ilegalidad de tales disposiciones e instando a dicho órgano jurisdiccional, que no es competente para declarar por sí mismo tal nulidad, a interrogar al TJUE al respecto por la vía de una remisión prejudicial, a menos que dichos justiciables hubieran sin la menor duda dispuesto del derecho a interponer, con arreglo al art. 263 TFUE, un recurso contra dichas disposiciones y que no hubieran ejercitado ese derecho en el plazo establecido para ello. Así pues, la remisión prejudicial para que se aprecie la validez de un acto constituye, de la misma manera que el recurso de anulación, una modalidad del control de legalidad de los actos de la Unión.

Esa característica esencial del sistema de tutela judicial de la Unión alcanza al control de legalidad de las decisiones por las que se establecen medidas restrictivas frente a personas físicas o jurídicas en el marco de la PESC. Ello se debe a que ni del Tratado UE ni del Tratado FUE se desprende que los recursos de anulación interpuestos ante el Tribunal General (TG), en aplicación conjunta de los arts. 256 TFUE y 263 TFUE, sean la única modalidad de control de legalidad de las decisiones por las que se establezcan medidas restrictivas frente a personas físicas o jurídicas y que, por tanto, en concreto 
la remisión prejudicial para que se aprecie la validez de un acto no constituya una modalidad de dicho control de legalidad. A ese respecto, cuando el art. 24 TUE, apdo. 1, párr. segundo, última frase, remite al art. 275 TFUE, párr. segundo, no lo hace para determinar el tipo de procedimiento en que el TJUE puede controlar la legalidad de determinadas decisiones, sino para fijar el tipo de decisiones cuya legalidad puede ser controlada por el TJUE en cualquier procedimiento cuyo objeto sea ese mismo control de legalidad. Pues bien, dado que la aplicación de una decisión por la que se establezcan medidas restrictivas frente a personas físicas o jurídicas es en parte responsabilidad de los Estados miembros, la remisión prejudicial para que se aprecie la validez de un acto cumple una función esencial a la hora de garantizar la tutela judicial efectiva, en particular cuando, tal como sucede en el asunto principal, en un procedimiento judicial nacional se cuestiona la legalidad tanto de las medidas nacionales de aplicación como de la propia decisión adoptada en materia de PESC en que se basen dichas medidas nacionales. En efecto, habida cuenta de que los Estados miembros deberán velar por la conformidad de sus políticas nacionales con las posiciones de la Unión que se hayan adoptado mediante decisiones del Consejo adoptadas en virtud del art. 29 TUE, el acceso al control judicial de esas decisiones resulta imprescindible cuando prevén la adopción de medidas restrictivas frente a personas físicas o jurídicas.

La existencia misma de un control jurisdiccional efectivo para garantizar el cumplimiento de las disposiciones del derecho de la Unión es inherente a la existencia de un Estado de derecho. Si bien el art. 47 de la Carta no puede crearle al TJUE una competencia cuando los Tratados excluyen esa posibilidad, el principio de tutela judicial efectiva conlleva que la exclusión de la competencia del TJUE en materia de PESC debe interpretarse restrictivamente.

En estas circunstancias, y puesto que el TJUE dispone, en virtud del art. 24 TUE, apdo. 1, y del art. 275 TFUE, párr. segundo, de competencia material para pronunciarse sobre la validez de actos de la Unión, en particular, cuando se trata de medidas restrictivas frente a personas físicas o jurídicas, resultaría contrario a la sistemática de la tutela judicial efectiva instaurada por los Tratados interpretar esa última disposición en el sentido de que excluye la posibilidad de que los tribunales de los Estados miembros planteen al TJUE cuestiones relativas a la validez de decisiones del Consejo por las que se establezca la adopción de dichas medidas.

Por último, desestima la alegación de que, al no tener competencia el TJUE para pronunciarse con carácter prejudicial sobre la validez de las decisiones adoptadas en materia de PESC mediante las que se establezca la adopción de medidas restrictivas frente a personas físicas o jurídicas, corresponde exclusivamente a los tribunales nacionales garantizar la tutela judicial efectiva. Ello se debe a que, según jurisprudencia reiterada, la necesaria coherencia del 
sistema de protección judicial exige que la facultad de declarar la nulidad de los actos de las instituciones de la Unión, si se plantea ante un órgano jurisdiccional nacional, esté reservada al TJUE en el marco del art. 267 TFUE. La misma conclusión resulta obligada por lo que se refiere a las decisiones adoptadas en materia de PESC y respecto de las que los Tratados confieren al TJUE competencia para el control de legalidad. Asimismo, es el TJUE el que está en mejores condiciones para pronunciarse sobre la validez de los actos de la Unión, habida cuenta de las posibilidades de que dispone en el contexto del procedimiento prejudicial para, por una parte, recabar las observaciones de los Estados miembros y de las instituciones de la Unión cuyos actos se cuestionan y, por otra parte, pedir a los Estados miembros y a las instituciones, los órganos o los organismos de la Unión que no sean partes en el litigio todas las informaciones que considere necesarias a efectos procesales.

\section{Un órgano jurisdiccional que resuelve en última instancia puede abste- nerse de plantear una cuestión prejudicial al TJUE cuando un recurso de casación es rechazado por causas de inadmisibilidad propias del pro- cedimiento ante ese órgano jurisdiccional, siempre y cuando se respeten los principios de equivalencia y de efectividad (Sentencia de 15 de mar- zo de 2017, Lucio Cesare Aquino, C-3/16, EU:C:2017:209).}

Esta petición de decisión prejudicial se presentó en el contexto de un recurso por responsabilidad extracontractual y planteaba cuestiones interpretativas sobre el art. 267 TFUE, párr. tercero (obligación de los tribunales nacionales de última instancia de plantear una petición de decisión prejudicial) y sobre los arts. 47, párr. segundo de la Carta (derecho a ser oído por un juez imparcial e independiente, establecido previamente por la ley), en una situación en la que una norma de procedimiento nacional impedía que se aceptase la solicitud de que se planteara una cuestión prejudicial al TJUE. En el litigio principal se denegó dicha solicitud por haber sido formulada por el demandante en un escrito procesal que, debido a su tardía fecha de presentación, no podía ser tenido en cuenta.

En primer lugar, el TJUE estimó que una norma nacional según la que se presume que el recurrente ha desistido del recurso de casación cuando no ha solicitado la continuación del procedimiento en un plazo de treinta días a partir del día en que se le haya notificado el informe del magistrado instructor que dictamina que el recurso es inadmisible o infundado no altera en modo alguno el hecho de que las resoluciones del tribunal contra las que se formuló el recurso de casación pueden ser impugnadas ante una instancia superior $y$, por tanto, emanan de un órgano jurisdiccional que no resuelve en última instancia. En la medida en que el tribunal de la instancia inferior no se considera 
un órgano jurisdiccional que resuelve en última instancia, el TJUE concluyó que no precedía responder a la cuestión sobre las consecuencias de la presentación de una solicitud de que se plantee una cuestión prejudicial fuera de plazo.

En segundo lugar, el TJUE consideró que el art. 267 TFUE, párr. tercero, debe interpretarse en el sentido de que un órgano jurisdiccional que resuelve en última instancia puede abstenerse de plantear una cuestión prejudicial al TJUE cuando un recurso de casación es rechazado por causas de inadmisibilidad propias del procedimiento ante ese órgano jurisdiccional, de acuerdo con el derecho procesal nacional, siempre y cuando se respeten los principios de equivalencia y de efectividad. Por una parte, el principio de equivalencia exige que el conjunto de normas aplicables a los recursos se aplique indistintamente a los recursos basados en la violación del derecho de la Unión y a aquellos, similares, basados en la infracción del derecho interno, lo que parecía cumplirse en el asunto de autos. Por otra parte, en lo que atañe al principio de efectividad, una norma procesal nacional no debe hacer imposible en la práctica o excesivamente difícil el ejercicio de los derechos conferidos por el ordenamiento jurídico de la Unión. Para el TJUE, tampoco quedó de manifiesto que este principio no fuera observado en el litigio principal. En efecto, el Tribunal de Casación belga declaró, en virtud de normas procesales internas, la inadmisibilidad de los motivos invocados por el recurrente en el litigio principal en apoyo del recurso de casación presentado contra la resolución del tribunal inferior, debido a que, si bien el interesado, mediante estos motivos, impugnaba una de las apreciaciones desfavorables en que se basó el último órgano jurisdiccional citado para desestimar su solicitud de libertad condicional, las demás apreciaciones desfavorables de dicho órgano jurisdiccional permitían justificar por sí solas esa resolución.

El incumplimiento del deber de diligencia por parte del Defensor del Pueblo Europeo no constituye automáticamente un comportamiento ilícito que genere la responsabilidad de la Unión, sino que es necesario demostrar que este rebasó de manera manifiesta y grave los límites impuestos a su facultad de apreciación en el contexto del ejercicio de las facultades de investigación de que dispone y tomando en cuenta todas las circunstancias que caractericen la situación de que se trate (Sentencia de 4 de abril 2017, Defensor del Pueblo Europeo / Claire Staelen, C-337/15 P, EU:C:2017:256).

Mediante esta sentencia, el TJUE anuló parcialmente la sentencia del TG (asunto T-217/11) en la que falló que el defensor del pueblo europeo había incurrido en un incumplimiento lo suficientemente caracterizado por una serie de irregularidades, entre ellos, la observancia del deber de diligencia, en 
la tramitación de las investigaciones llevadas a cabo por el defensor en relación con un caso de mala administración del Parlamento en lo que concernía a la gestión de la lista de aptitud resultante de una oposición general en la que la demandante, Sra. Staelen, figuraba como candidata aprobada. Estos comportamientos del defensor del pueblo europeo generaron así la responsabilidad extracontractual de la Unión.

En cuanto a la observancia del deber de diligencia, el TJUE consideró que su incumplimiento no constituye automáticamente un comportamiento ilícito que genere la responsabilidad de la Unión, sino que ha de ser apreciado tomando en consideración el hecho de que, en el desempeño de su misión, el Defensor del Pueblo está únicamente sujeto a una obligación de medios y goza de un amplio margen de apreciación sobre el fundamento de las reclamaciones que recibe y al curso que conviene darles y sobre el modo de llevar a cabo las investigaciones, así como sobre el análisis de los datos recabados y las conclusiones que procede extraer de dicho análisis. Para considerar que existe una infracción suficientemente caracterizada como consecuencia del incumplimiento de la obligación de diligencia que pesa sobre el Defensor del Pueblo, es pues necesario demostrar que al no actuar con toda la minuciosidad y la prudencia debidas, este rebasó de manera manifiesta y grave los límites impuestos a su facultad de apreciación en el contexto del ejercicio de las facultades de investigación de que dispone y tomando en cuenta todas las circunstancias que caractericen la situación de que se trate, entre las que figuran, en particular, el carácter manifiesto de la falta de diligencia demostrada por el defensor del pueblo al llevar a cabo su investigación.

No obstante, el TJUE verificó si los diversos comportamientos controvertidos del defensor del pueblo debían ser calificados, en todo caso, como incumplimientos suficientemente caracterizados de la obligación de diligencia, concluyendo que algunos de estos comportamientos, a saber la desnaturalización del contenido de un dictamen del Parlamento, sí que lo era y fijó una indemnización de 7000 euros a la Sra. Staelen por daño moral (que es la misma cantidad que consideró el TG en la sentencia parcialmente anulada).

En los recursos de anulación en los que el TG realiza un control pleno de legalidad, el TG debe aplicar las normas de derecho nacional, tal y como las interpretan los órganos jurisdiccionales nacionales en la fecha en la que dicta su resolución (Sentencia de 5 de abril de 2017, Oficina de Propiedad Intelectual de la Unión Europea (EUIPO) / Szajner, C-598/14 P, EU:C:2017:265).

Mediante esta sentencia, el TJUE desestimó un recurso de casación interpuesto contra la sentencia del TG (asunto T-453/11) en la que este último 
anuló una resolución de la Sala de Recurso de a EUIPO en la que se había declarado la existencia de un riesgo de confusión entre la denominación social «Forge de Laguiole» y la marca Laguiole. El TJUE confirmó que la sociedad Forge de Laguiole puede oponerse al registro, a escala de la Unión, de la marca Laguiole, particularmente, en el ámbito de la cuchillería y los cubiertos. En cambio, la sociedad Forge de Laguiole no puede oponerse al registro de la marca Laguiole en los ámbitos en los que no desarrolla realmente una actividad.

Desde la perspectiva del derecho contencioso, la sentencia es interesante por su primer motivo de casación, en el que el TJUE señaló que, al apreciar la protección de la denominación de una sociedad por el derecho nacional de un Estado miembro, el TG debe aplicar las normas de derecho nacional tal como las interpretan los órganos jurisdiccionales nacionales en la fecha en la que dicta su resolución. Por lo tanto, debe poder tomar en consideración una resolución de un órgano jurisdiccional nacional (en este caso de la Cour de cassation francesa) dictada después de que la EUIPO adoptase su resolución. Por consiguiente, el TG concluyó acertadamente que, de conformidad con la normativa francesa aplicable en la materia, la protección que puede invocar Forge de Laguiole debido a su denominación social es válida únicamente para las actividades que dicha empresa desarrolla de manera efectiva. Este principio se aplica a situaciones en las que el TG efectúa un control pleno de legalidad. En efecto, en el asunto de autos, el TG ejercía este control pleno de legalidad, por lo que el control jurisdiccional efectuado por el TG acerca de la apreciación del derecho nacional realizada por la Sala de Recurso de la EIUPO puede llevar a la conclusión de que un hecho, revelado con posterioridad a la adopción de la resolución impugnada no puede obstar para que se corrija el error.

\section{MERCADO INTERIOR, LIBRE CIRCULACIÓN Y CIUDADANÍA EUROPEA}

Los Estados miembros pueden reservar a los notarios la legitimación de las firmas que consten en los documentos necesarios para la creación o la transferencia de derechos reales inmobiliarios y excluir, por consiguiente, la posibilidad de que en ese Estado miembro se reconozca tal legitimación cuando la haya efectuado, con arreglo a su derecho nacional, un abogado establecido en otro Estado miembro (Sentencia de 9 de marzo de 2017, Piringer, C-342/15, EU:C:2017:196).

La Sra. Piringer, propietaria de la mitad indivisa de un bien inmueble situado en Austria, solicitó la inscripción en el Registro de la Propiedad austria- 
co, a efectos de prioridad registral, una promesa de venta de su cuota indivisa sobre la referida finca. La firma de la solicitante que figuraba en la solicitud fue legitimada por un abogado checo que, conforme al derecho checo, expidió al efecto un testimonio de legitimación en el que se precisaban, entre otros datos, la fecha de nacimiento de la Sra. Piringer y los documentos aportados para probar su identidad. El abogado firmante confirmó además que la Sra. Piringer había firmado ante él de su puño y letra la solicitud, en un solo ejemplar. Las autoridades austríacas habían denegado esta solicitud, basándose en que la firma de la Sra. Piringer no había sido legitimada judicial ni notarialmente, según exigían las normas austríacas.

En el marco del litigio principal, entablado por la Sra. Piringer, el Tribunal Supremo Civil y Penal austríaco planteó al TJUE las cuestiones de si la directiva sobre la libre prestación de servicios por los abogados (Directiva 77/249/CEE del Consejo, dirigida a facilitar el ejercicio efectivo de la libre prestación de servicios por los abogados), así como el art. 56 del Tratado FUE permiten a un Estado miembro reservar a los notarios la facultad de legitimación de las firmas que consten en los documentos necesarios para la creación o la transferencia de derechos reales inmobiliarios y de excluir, de esta manera, la posibilidad de reconocimiento, en ese Estado miembro de una legitimación expedida por un abogado establecido en otro Estado miembro.

El TJUE primero señaló que Directiva 77/249, cuyo objetivo es facilitar el ejercicio efectivo de la libre prestación de servicios por los abogados, es aplicable a los antecedentes de hecho del asunto, puesto que el concepto de «actividad de abogacía» en el sentido de esta directiva no solo comprende los servicios jurídicos que habitualmente prestan los abogados, como el asesoramiento jurídico o la representación y la defensa de los clientes ante los tribunales, sino que puede aplicarse igualmente a otros tipos de prestaciones, como la legitimación de firmas. A este respecto es irrelevante el hecho de que estas últimas prestaciones no sean efectuadas por abogados en todos los Estados miembros.

Segundo, era necesario determinar si la actividad de abogacía consistente en la legitimación de firmas está sometida al régimen de la libre prestación de servicios. En efecto, la aplicación de la Directiva 77/249 a las actividades de abogacía está también supeditada al requisito de que dichas actividades sean ejercidas «en concepto de prestación de servicios». A este respecto, el TJUE recordó que el derecho a la libre prestación de servicios reconocido por el art. 56 TFUE y por la Directiva a los nacionales de los Estados miembros y, por lo tanto, a los ciudadanos de la Unión, comprende la libre prestación de servicios "pasiva", es decir, la libertad de los destinatarios de los servicios para desplazarse a otro Estado miembro con el fin de hacer uso del servicio, sin ser obstaculizados por restricciones. 
No obstante, el art. 1, apdo. 1, párr. segundo, de la Directiva 77/249 autoriza una excepción a la libre prestación de servicios por parte de los abogados al disponer que los Estados miembros podrán reservar a «determinadas categorías de abogados» la facultad de elaborar documentos auténticos relativos, en particular, a la creación o la transferencia de derechos reales inmobiliarios. El TJUE reconoce que el origen de esta disposición fue tomar en consideración la normativa aplicable en el Reino Unido e Irlanda, que atribuye a los solicitors la competencia exclusiva para extender determinados instrumentos jurídicos del ámbito del derecho inmobiliario, mientras que en los demás Estados miembros, en el momento de la adopción de esa directiva, la competencia para extender esos instrumentos estaba reservada a los notarios o a los tribunales. Por tanto, este art. no se aplica a una normativa de un Estado miembro que reserva a los notarios la legitimación de las firmas que consten en los documentos necesarios para la creación o la transferencia de derechos reales inmobiliarios y excluye, por consiguiente, la posibilidad de que en ese Estado miembro se reconozca tal legitimación cuando la haya efectuado un abogado establecido en otro Estado miembro.

Según el Tribunal, tal normativa tampoco infringe el art. 56 del Tratado, en virtud del cual se debe eliminar toda discriminación por razón de la nacionalidad en perjuicio del prestador de servicios establecido en otro Estado miembro, y suprimir cualquier restricción a la libre prestación de servicios, puesto que queda justificada por razones imperiosas de interés general. En efecto, la normativa austríaca, al no permitir que se reconozca la legitimación de una firma efectuada por un abogado establecido en otro Estado miembro donde presta legalmente, con arreglo al derecho nacional, servicios análogos, puede impedir que este profesional ofrezca ese tipo de prestación a los clientes interesados en servirse de ella en Austria y, por tanto, constituye una restricción a la libre prestación de servicios garantizada por el art. 56. No obstante, las disposiciones nacionales que exigen que se recurra a profesionales fedatarios, como los notarios, para verificar la exactitud de las inscripciones practicadas en un registro de la propiedad contribuyen a garantizar la seguridad jurídica de las transacciones inmobiliarias y el buen funcionamiento del registro de la propiedad, y entroncan, en términos más generales, con la protección de la buena administración de justicia, la cual constituye una razón imperiosa de interés general, y se consideran una medida adecuada y proporcional para alcanzar los objetivos perseguidos.

El certificado E 101 expedido un Estado miembro vincula tanto a las instituciones de seguridad social del Estado miembro en el que se efectúe el trabajo como a los órganos jurisdiccionales de ese Estado miembro, aun cuando estos comprueben que las condiciones en que se desarrolla 


\section{la actividad del trabajador de que se trate quedan manifiestamente fuera del ámbito de aplicación material del Reglamento 1408/71 (Sentencia de 27 de abril de 2017, A-Rosa Flussschiff, C-620/15, EU:C:2017:309).}

Esta petición de decisión prejudicial se presentaba por el Tribunal de Casación francés en el contexto de un litigio entre A-Rosa Flussschiff, una empresa alemana con sucursal en Suiza y que explota dos buques de crucero que navegan exclusivamente en aguas interiores francesas, y el organismo de recaudación de cotizaciones a la seguridad social y de prestaciones familiares de Alsacia y la Caja de Seguridad Social del Cantón de los Grisones, Suiza, en relación con una reclamación de deuda, notificada por el organismo a A-Rosa, por impago al régimen francés de seguridad social de cotizaciones correspondientes al período comprendido entre el 1 de abril de 2005 y el 30 de septiembre de 2007. Con ocasión de inspecciones por parte de las autoridades francesas, la empresas suministró certificados E 101 expedidos por la Caja de Seguridad Social suiza, ya que había sido la sucursal suiza la que empleaba al personal de los cruceros.

Las cuestiones planteadas tienen por objeto la interpretación del art. 14, apdo. 2, letra a), del Reglamento 1408/71 del Consejo, relativo a la aplicación de los regímenes de seguridad social a los trabajadores por cuenta ajena, a los trabajadores por cuenta propia y a los miembros de sus familias que se desplazan dentro de la Comunidad, y del art. 12 bis, punto 1 bis, del Reglamento (CEE) 574/72 del Consejo, por el que se establecen las modalidades de aplicación del Reglamento 1408/71, en virtud del cual la institución designada por la autoridad competente del Estado miembro cuya legislación es aplicable — con arreglo al art. 14, apdo. 2, letra a), del Reglamento 1408/71-, estaba obligada a expedir el certificado E 101, en el que se hiciera constar que el trabajador de que se trataba estaba sujeto a la legislación de dicho Estado miembro. Según el Acuerdo sobre la Libre Circulación de Personas entre la Comunidad Europea y sus Estados miembros, por una parte, y la Confederación Suiza, de 1999, extiende el ámbito de aplicación de los citados reglamentos también a Suiza.

En la línea de una jurisprudencia asentada, el TJUE señaló, en primer lugar, que mediante el certificado E 101 la institución competente del Estado miembro en el que esté establecida la empresa que emplea a los trabajadores de que se trate declara que su propio régimen de seguridad social seguirá siendo aplicable a dichos trabajadores. De este modo, en virtud del principio según el cual los trabajadores deben estar afiliados a un solo régimen de seguridad social, este certificado implica necesariamente que no puede aplicarse el régimen de otro Estado miembro. Ahora bien, el TJUE estimó que las obligaciones de cooperación que derivan del art. 4 TUE, apdo. 3, así como los 
objetivos del art. 14, apdo. 2, letra a), del Reglamento 1408/71 y del art. 12 bis, punto 1 bis, del Reglamento 574/72, no se cumplirían si la institución de dicho Estado miembro en el cual se efectúa el trabajo considerase que no está vinculada por las menciones del certificado E 101 y sometiese también a esos trabajadores a su propio régimen de seguridad social.

Por ello, hasta tanto no se retire o se declare la invalidez del certificado E 101, la institución competente del Estado miembro en el que el trabajador efectúa un trabajo debe tener en cuenta el hecho de que este ya está sometido a la legislación de seguridad social del Estado donde está establecida la empresa que lo emplea y, por consiguiente, esa institución no puede someter al trabajador en cuestión a su propio régimen de seguridad social. El hecho de que los trabajadores de que se trate queden manifiestamente fuera del ámbito de aplicación de dicho art. 14 no modifica en modo alguno las consideraciones anteriores. En la medida en que el certificado E 101 vincula a la institución competente del Estado miembro de acogida, nada justifica que la persona que utiliza los servicios de un trabajador pueda hacer caso omiso de dicho certificado. No obstante, si esa persona tuviese dudas sobre la validez del certificado, deberá informar de ello a la institución de que se trate.

Por último, el hecho de que el Estado que ha emitido los certificados $\mathrm{E}$ 101 sea la Confederación Suiza y de que, por tanto, no pueda interponerse un eventual recurso por incumplimiento contra dicho Estado, no afecta en absoluto al carácter vinculante de los certificados E 101 controvertidos en el litigio principal, ya que el Acuerdo CE-Suiza establece su propio sistema de solución de diferencias entre las partes contratantes.

\section{COMPETENCIA}

En un procedimiento ordinario respecto a la investigación de la participación en un cártel aplicable a los presuntos partícipes que no acuerdan una transacción con la Comisión, la Comisión no está vinculada, con respecto a estos partícipes, por el intervalo de las probables multas comunicado en el procedimiento de transacción (Sentencia de 12 de enero de 2017, Timab Industries y Cie financière et de participations Roullier (CFPR) / Comisión, C-411/15 P, EU:C:2017:11).

En el procedimiento de casación que dio lugar a esta sentencia, el TJUE confirmó la multa de casi sesenta millones de euros impuesta al grupo Roullier en relación con el cártel de los fosfatos. No obstante, la sentencia resulta de interés por ser el primer caso híbrido de cártel, ya que el procedimiento 
ordinario (aplicable al grupo Roullier) se desarrolló simultáneamente con el procedimiento de transacción (de aplicación a los demás partícipes del cártel).

En el año 2010, la Comisión impuso varias multas por importe de 175 647000 euros a seis grupos de fabricantes que habían participado en un cártel sobre los precios y se habían repartido el mercado de los fosfatos destinados a la alimentación animal durante más de treinta años. En el ámbito de este cártel, las empresas en cuestión se repartieron cuotas de venta por región y por cliente, y coordinaron entre sí los precios y, en algunos casos, las condiciones de venta. El grupo Roullier, del que Timab Industries es una filial, fue objeto de una multa de 59850000 euros por haber participado en dicho cártel entre los años 1993 y 2004.

Contrariamente a los otros grupos involucrados en el cártel, el grupo Roullier no quiso acordar una transacción con la Comisión después de tener conocimiento del importe aproximado de la multa que la Comisión preveía imponerle en el procedimiento de transacción. El objetivo de la transacción es simplificar el procedimiento, pues las empresas de que se trata admiten su participación en el cártel y aceptan compromisos obligatorios a cambio de una reducción del $10 \%$ del importe de la multa. Por lo tanto, la Comisión aplicó el procedimiento ordinario respecto al grupo Roullier.

El grupo Roullier reprochaba principalmente a la Comisión que le hubiera aplicado una multa superior al máximo del intervalo contemplado durante el procedimiento de transacción. Mediante sentencia de 20 de mayo de 2015 (T-456/10), el TG desestimó el recurso del grupo Roullier, al considerar, fundamentalmente, que la Comisión no había sancionado al grupo Roullier por retirarse del procedimiento de transacción, y que no estaba vinculada por el intervalo de multas comunicado en el procedimiento de transacción, extremos que fue confirmado por el TJUE en casación.

En particular, la Comisión, siguiendo la misma metodología utilizada para el intervalo de multas señalado al grupo Roullier en el procedimiento de transacción, efectuó válidamente una revisión del importe de la multa. En efecto, el TJUE señaló, al igual que el TG, que la Comisión tuvo que tener en cuenta, en el procedimiento ordinario, los datos informativos nuevos que la obligaron a revisar el expediente, a definir nuevamente la duración del cártel y a modificar la multa prescindiendo de aplicar las reducciones que había propuesto en el procedimiento de transacción. A este respecto, el TJUE señala en particular que, en el procedimiento de transacción, el grupo Roullier no había negado la duración del cártel tomada en consideración por la Comisión (1978-2004), mientras que, en el procedimiento ordinario, alegó (con éxito) que su participación en el cártel se limitaba a los años 1993-2004. Por lo tanto, el grupo Roullier debía contar con que la negación de su participación en 
el cártel durante el período comprendido entre 1978 y 1993 influyera en las reducciones que se le podían conceder al fijar la multa.

Esta paradoja, que conduce a una multa mayor por una duración de la infracción más corta, se explica porque la Comisión se había mostrado dispuesta, en el procedimiento de transacción, a conceder reducciones adicionales al grupo Roullier por la información proporcionada por dicho grupo respecto al período 1978-1993. Dado que el grupo Roullier negó posteriormente su participación en el cártel durante ese período, la Comisión consideró que ya no tenía razón de ser lo esencial de las reducciones propuestas para el período 1993-2004. El cambio de postura del grupo Roullier también explica por qué este no puede acogerse al principio de confianza legítima en el mantenimiento de las estimaciones comunicadas por la Comisión durante el procedimiento de transacción.

El escrito preliminar enviado de parte de la Comisión a un Estado miembro en el marco de un procedimiento de ayudas existentes constituye una primera etapa de la elaboración de la decisión final, por lo que se puede alegar la ilegalidad de que adolece la apreciación contenida en ese escrito en apoyo de un recurso de anulación contra la decisión final; las medidas apropiadas que la Comisión propone en aplicación del art. 108 TFUE, apdo. 1, en cuanto son aceptadas por un Estado miembro, tienen un efecto vinculante respecto de ese Estado miembro, y producen efectos jurídicos, solo si se comunican la Comisión y si esta toma nota de ella e informa al citado Estado miembro, mediante decisión (Sentencia de 15 de marzo de 2017, Stichting Woonpunt / Comisión, C-415/15 P, EU:C:2017:216)

En el ámbito de las ayudas de Estado, conviene destacar esta sentencia mediante la que el TJUE anula, por segunda vez, un auto del TG en el marco del mismo procedimiento (en este caso T-203/10 RENV). En un primer momento, el TJUE anuló el auto del TG que declaraba el recurso de anulación inadmisible. Con esta sentencia mostró su desacuerdo con el TG sobre el fondo del asunto.

Las recurrentes son sociedades promotoras de viviendas sociales con domicilio en los Países Bajos, destinadas fundamentalmente a personas y a colectivos socialmente desfavorecidos y que recibían ayudas de las autoridades neerlandesas como compensación por la prestación de un servicio público. En 2005, la Comisión envió a las autoridades neerlandesas un escrito con arreglo al art. 17 del Reglamento 659/1999 (Reglamento 2015/2282 en su versión codificada), en el que calificaba el sistema general de ayudas de Estado abonadas en favor de las promotoras de ayudas existentes y expresaba dudas acerca 
de su compatibilidad con el mercado interior. Con carácter preliminar, la Comisión indicó que las autoridades neerlandesas debían modificar la misión de servicio público encomendada a las promotoras, de tal manera que la vivienda social se reservara para un grupo de destinatarios claramente definido de personas o de colectivos socialmente desfavorecidos. Añadió que las promotoras debían llevar a cabo todas sus actividades comerciales en condiciones de mercado y que estas actividades no podían beneficiarse de ayudas de Estado. Por último, señaló que la oferta de vivienda social debía adaptarse a la demanda de las personas o colectivos socialmente desfavorecidos. En 2009, las autoridades neerlandesas aceptaron las medidas apropiadas propuestas por la Comisión y comunicaron a esta sus compromisos dirigidos a modificar el sistema general de ayudas de Estado en favor de las promotoras con arreglo a las exigencias de la Comisión. En consecuencia de la aceptación de las medidas apropiadas, el 15 de diciembre de 2009, la Comisión adoptó la decisión controvertida declarando las ayudas compatibles con el art. 106, apdo. 2, del Tratado.

Las promotoras recurrieron la decisión de la Comisión mediante recurso de anulación, que fue desestimado por el TG al considerar que los motivos que habían planteado ante el mismo se referían en realidad al contenido del escrito del art. 17 y no al contenido de la decisión final de la Comisión. En efecto, el TG consideró en esencia que las recurrentes no impugnaban la apreciación efectuada por la Comisión, en la decisión controvertida, acerca de la compatibilidad del régimen de ayudas existente en su versión modificada por los compromisos adoptados por las autoridades neerlandesas, sino al examen efectuado por la Comisión del sistema de financiación de las promotoras como figuraba en la normativa neerlandesa inicial, antes de su modificación por los compromisos adoptados por esas autoridades y que ese examen no figuraba en la decisión controvertida sino en el escrito del art. 17.

Para el TJUE, el escrito del art. 17 constituye una primera etapa de la elaboración de la decisión controvertida, por lo que no puede impedirse a las recurrentes alegar la ilegalidad de que adolece la apreciación contenida en ese escrito en apoyo de su recurso contra la decisión final, aún más cuando las medidas apropiadas propuestas por la Comisión coinciden en esencia con las indicaciones que la Comisión había dado con carácter preliminar a las autoridades neerlandesas en el escrito del art. 17.

Por añadidura, el TJUE confirmó que las medidas apropiadas que la Comisión propone en aplicación del art. 108, apdo. 1 del Tratado en cuanto son aceptadas por un Estado miembro, tienen un efecto vinculante respecto de ese Estado miembro, como establece el art. 19, apdo. 1, segunda frase, del Reglamento 659/1999. No obstante, esa aceptación solo produce efectos jurídicos si se comunica la Comisión y si esta toma nota de ella e informa al citado Estado miembro, de conformidad con el art. 19, apdo. 1, primera 
frase, de ese Reglamento, mediante decisión. De ese modo, incumbía al TG examinar el fundamento de las alegaciones de las recurrentes, según las cuales la Comisión se había excedido supuestamente en su competencia al exigir medidas apropiadas y hacerlas vinculantes en la decisión controvertida, con independencia de la cuestión de las funciones respectivas de la Comisión y de los Estados miembros para la adopción de las medidas apropiadas. Como este examen incumbe al TG, el TJUE precedió devolver el asunto, de nuevo, al TG, para que este último resuelva.

\section{APROXIMACION DE LEGISLACIONES}

El principio de igualdad de trato no se opone a que el suministro de libros, periódicos y revistas digitales por vía electrónica se excluya de la aplicación de un tipo reducido de IVA (Sentencia de 7 de marzo de 2017, RPO, C-390/15, EU:C:2017:174).

De conformidad con la Directiva 2006/112/CE del Consejo, relativa al sistema común del IVA, en la versión resultante de la Directiva 2009/47/CE del Consejo, los Estados miembros pueden aplicar un tipo reducido de IVA a las publicaciones impresas como libros, periódicos y revistas. Por el contrario, las publicaciones digitales deben someterse al tipo impositivo normal, con excepción de los libros digitales suministrados mediante un soporte físico como, por ejemplo, un CD-ROM. En este caso cabe aplicar un tipo reducido de IVA a los libros digitales. Por el contrario, si se transmiten mediante descarga o por streaming, se aplica el tipo impositivo normal. En el caso de periódicos y revistas digitales se aplica siempre el tipo impositivo normal, con independencia de cómo se suministren. El Tribunal Constitucional polaco, que conocía del asunto a instancias del Defensor del Pueblo, dudaba de la validez de esta diferencia impositiva.

El TJUE constata en su sentencia, en primer lugar, que, en la medida en que la Directiva del IVA tiene como efecto excluir la aplicación de un tipo reducido de IVA al suministro de libros digitales por vía electrónica, mientras que se autoriza su aplicación al suministro de libros digitales en cualquier medio de soporte físico, debe considerarse que tales disposiciones establecen una diferencia de trato entre dos situaciones que, no obstante, son comparables con respecto al objetivo perseguido por el legislador de la Unión al permitir la aplicación de un tipo reducido de IVA a determinados tipos de libros, que es favorecer la lectura.

A continuación, el TJUE recuerda que una diferencia de trato está justificada cuando está en relación con un objetivo legalmente admisible persegui- 
do por la medida que tenga como efecto establecer tal diferencia y esta es proporcionada a dicho objetivo. Así pues, al adoptar una medida de naturaleza fiscal, el legislador de la Unión está llamado a tomar decisiones de naturaleza política, económica y social y a establecer una jerarquía entre intereses divergentes o a realizar apreciaciones complejas. Por tanto, en este marco se le debe reconocer un amplio margen de apreciación, de forma que el control judicial de tales requisitos debe limitarse a controlar si hay un error manifiesto. En este contexto, el TJUE observa que la exclusión de la aplicación de un tipo reducido de IVA al suministro de libros digitales por vía electrónica es consecuencia del régimen especial de IVA aplicable al comercio electrónico. En efecto, debido a la evolución permanente a la que están sometidos todos los servicios electrónicos, se estimó necesario someterlos a normas claras, simples y uniformes para que el tipo de IVA aplicable pueda determinarse con certeza, de modo que se facilite la gestión de este impuesto a los sujetos pasivos y a las administraciones tributarias nacionales. Al excluir la aplicación de un tipo reducido de IVA a los servicios suministrados por vía electrónica, el legislador de la Unión evita que los sujetos pasivos y las administraciones tributarias nacionales tengan que examinar, en el caso de cada uno de los tipos de estos servicios, si está comprendido en una de las categorías de servicios a las que es aplicable el tipo reducido en virtud de la Directiva del IVA. En consecuencia, considera que tal medida es idónea para alcanzar el objetivo perseguido por el régimen especial de IVA aplicable al comercio electrónico. Por otra parte, admitir que los Estados miembros disponen de la posibilidad de aplicar un tipo reducido de IVA al suministro de libros digitales por vía electrónica, como ocurre en el caso del suministro de tales libros en cualquier medio de soporte físico, menoscabaría la coherencia global de la medida instaurada por el legislador de la Unión, consistente en excluir todos los servicios electrónicos de la posibilidad de aplicar un tipo reducido de IVA.

La venta de un reproductor multimedia que permite ver gratuita y fácilmente en una pantalla de televisión películas disponibles ilegalmente en internet puede constituir una vulneración de los derechos de autor, pues la reproducción temporal en dicho reproductor de una obra protegida por derechos de autor obtenida mediante streaming no está exenta del derecho de reproducción (Sentencia de 26 de abril de 2017, Brein, C-527/15, EU:C:2017:300).

El Sr. Wullems vende en internet distintos modelos de un reproductor multimedia que, según la publicidad, permite, en particular, ver gratuita y fácilmente en una pantalla de televisión material audiovisual disponible en internet sin la autorización de los titulares de los derechos de autor. Stichting 
Brein, una fundación neerlandesa que defiende los intereses de los titulares de derechos de autor, solicitó a un tribunal de primera instancia neerlandés que ordenara al Sr. Wullems que dejara de comercializar reproductores multimedia o de ofertar hiperenlaces que proporcionen a los usuarios acceso ilegal a obras protegidas. Sostenía que, mediante la comercialización del reproductor multimedia, se efectúa una "comunicación al público», conculcando la normativa neerlandesa sobre derechos de autor que transpone la Directiva 2001/29 del Parlamento Europeo y del Consejo, relativa a la armonización de determinados aspectos de los derechos de autor y derechos afines a los derechos de autor en la sociedad de la información, en particular, su art. 3.

El TJUE confirma que la venta de un reproductor multimedia como el controvertido constituye una "comunicación al público" en el sentido de la Directiva. Recuerda a este respecto su jurisprudencia según la cual la Directiva 2001/29/CE tiene como objetivo la instauración de un nivel elevado de protección en favor de los autores. Por tanto, el concepto de «comunicación al público» debe entenderse en un sentido amplio. Además, el TJUE ya ha declarado que el hecho de facilitar en una página de internet enlaces sobre los que se puede pulsar y que conducen a obras protegidas publicadas sin ninguna restricción de acceso en otra página de internet, ofrece a los usuarios de la primera página un acceso directo a dichas obras. Así sucede también cuando se vende el reproductor multimedia controvertido.

Del mismo modo, el Sr. Wullems preinstala en el reproductor multimedia, con pleno conocimiento de las consecuencias de su comportamiento, extensiones que permiten acceder a obras protegidas y visualizarlas en una pantalla de televisión. Tal actividad no se confunde con la mera puesta a disposición de instalaciones materiales mencionada en la Directiva. Los sitios de internet de difusión en flujo continuo no son fácilmente identificables por el público y, en la mayoría de los casos, cambian a menudo.

El TJUE subraya igualmente que, según el órgano jurisdiccional remitente, el reproductor multimedia ha sido adquirido por un número considerable de personas. Además, la comunicación tiene como destinatarios a todos los compradores potenciales de dicho reproductor que disponen de una conexión a internet. Así, dicha comunicación se dirige a un número indeterminado de destinatarios potenciales e implica un número considerable de personas. Además, la venta de dicho reproductor multimedia se realiza con la finalidad de obtener un beneficio, ya que el precio pagado por el reproductor se abona principalmente para poder acceder directamente a las obras protegidas disponibles en sitios de difusión en flujo continuo sin la autorización de los titulares de los derechos de autor.

El TJUE ha declarado igualmente que los actos de reproducción temporal, en el referido reproductor multimedia, de una obra protegida por derechos 
de autor obtenida mediante streaming desde un sitio de internet perteneciente a un tercero en el que la referida obra se ofrece sin autorización del titular de los derechos de autor, no están exentos del derecho de reproducción. En virtud de la Directiva, un acto de reproducción no estará exento del derecho de reproducción a menos que cumpla cinco requisitos, a saber: a) que sea un acto provisional; b) que sea transitorio o accesorio; c) que forme parte integrante y esencial de un proceso tecnológico; d) que su única finalidad consista en facilitar una transmisión en una red entre terceras partes por un intermediario o una utilización lícita de una obra o prestación protegidas, y e) que no tenga por sí mismo una significación económica independiente. Dichos requisitos son acumulativos, de modo que la inobservancia de tan solo uno de estos acarrea que el acto de reproducción no quede exento. Además, la excepción solo es aplicable en determinados casos concretos que no entren en conflicto con la explotación normal de la obra o prestación y no perjudiquen injustificadamente los intereses legítimos del titular del derecho.

En el caso de autos, y habida cuenta, en particular, del contenido de la publicidad realizada para el reproductor multimedia y de la circunstancia de que el principal atractivo de dicho reproductor es que en él están preinstaladas ciertas extensiones, el TJUE considera que el comprador de tal reproductor accede de manera deliberada y con conocimiento de causa a una oferta gratuita y no autorizada de obras protegidas. Además, los actos de reproducción temporal en el reproductor multimedia controvertido de obras protegidas por derechos de autor, pueden entrar en conflicto con la explotación normal de tales obras y perjudicar injustificadamente los intereses legítimos del titular de los derechos de autor, puesto que tales actos dan lugar normalmente a una disminución de las transacciones legales relativas a dichas obras protegidas.

\section{No existe derecho al olvido en relación con los datos personales reco- gidos en el registro de sociedades (Sentencia de 9 de marzo de 2017, Manni, C-398/15, EU:C:2017:197).}

El Sr. Salvatore Manni, administrador único de una sociedad a la que se adjudicó un contrato para la construcción de un complejo turístico en Italia, interpuso una demanda contra la Cámara de Comercio de Lecce. A su juicio, los inmuebles de dicho complejo no se vendían porque en el registro de sociedades constaba que había sido administrador de otra sociedad, declarada en concurso de acreedores en 1992 y liquidada en 2005. La Corte Suprema di Cassazione (Tribunal de Casación de Italia), ha planteaba al TJUE varias cuestiones prejudiciales. Desea saber si la Directiva 95/46/CE del Parlamento Europeo y del Consejo, relativa a la protección de las personas físicas en lo que respecta al tratamiento de datos personales y a la libre circulación de estos 
datos, y la Directiva 68/151/CEE del Consejo, primera Directiva tendente a coordinar, para hacerlas equivalentes, las garantías exigidas en los Estados miembros a las sociedades definidas en el segundo párr. del art. 58 del Tratado, para proteger los intereses de socios y terceros, en su versión modificada, se oponen a que cualquier persona pueda acceder, sin límite en el tiempo, a los datos relativos a las personas físicas que figuran en el registro de sociedades.

El TJUE señala antes de nada que la publicidad de los registros de sociedades tiene por objeto garantizar la seguridad jurídica en las relaciones entre las sociedades y los terceros y proteger, en particular, los intereses de los terceros en relación con las sociedades anónimas y las sociedades de responsabilidad limitada, ya que dichas sociedades solo ofrecen su patrimonio social como garantía respecto a ellos. Además, el TJUE observa que pueden producirse situaciones en las que se necesita disponer de datos personales recogidos en el registro de sociedades incluso muchos años después de que una empresa se haya liquidado. En efecto, habida cuenta a) de la multitud de derechos y relaciones jurídicas que pueden vincular a una sociedad con actores en varios Estados miembros (aun tras su liquidación), y b) de la heterogeneidad de los plazos de prescripción previstos por las diferentes normativas nacionales, resulta imposible identificar un plazo único a cuya expiración la inscripción de estos datos en el registro y su publicidad ya no sea necesaria.

En estas circunstancias, los Estados miembros no pueden garantizar a las personas físicas cuyos datos están inscritos en el registro de sociedades el derecho a obtener, tras un determinado plazo a contar desde la liquidación de la sociedad de que se trate, la supresión de los datos personales que les conciernen. El TJUE considera que esta injerencia en los derechos fundamentales de los interesados (concretamente, en el derecho al respeto de la vida privada y el derecho a la protección de datos personales, garantizados por la Carta de los Derechos Fundamentales de la Unión) no es desproporcionada, en la medida en que a) en el registro de sociedades solo está inscrito un número limitado de datos personales, y b) está justificado que las personas físicas que deciden participar en los intercambios económicos mediante una sociedad anónima o una sociedad de responsabilidad limitada, que solo ofrecen su patrimonio social como garantía respecto a terceros, estén obligadas a hacer públicos los datos relativos a su identidad y a sus funciones dentro de aquellas.

No obstante, el TJUE no excluye que, en situaciones concretas, razones legítimas relativas propias de la situación particular del interesado puedan justificar, excepcionalmente, que el acceso a los datos personales que le conciernen inscritos en el registro se limite, al expirar un plazo suficientemente largo tras la liquidación de la sociedad de que se trate, a los terceros que justifiquen un interés específico en su consulta. Tal limitación del acceso a los datos personales debe realizarse sobre la base de una apreciación caso por caso. Incumbe a 
cada Estado miembro decidir si desea establecer esta limitación del acceso en su ordenamiento jurídico.

\section{DERECHO SOCIAL}

La Directiva relativa al establecimiento de un marco general para la igualdad de trato en el empleo y la ocupación permite una normativa de un Estado miembro que confiere a los trabajadores por cuenta ajena con determinados tipos de discapacidad una protección especial ex ante frente al despido, sin conferir tal protección a los funcionarios con discapacidades del mismo tipo, a menos que se compruebe una vulneración del principio de igualdad de trato (Sentencia de 9 de marzo de 2017, Milkova, C-406/15, EU:C:2017:198).

El TJUE concluye en esta sentencia que el art. 7, apdo. 2, de la Directiva 2000/78/CE del Consejo, relativa al establecimiento de un marco general para la igualdad de trato en el empleo y la ocupación, a la luz de la Convención de las Naciones Unidas sobre los derechos de las personas con discapacidad, aprobada en nombre de la Comunidad Europea mediante la Decisión 2010/48/CE del Consejo, y atendiendo al principio general de igualdad de trato, consagrado en los arts. 20 y 21 de la Carta de los Derechos Fundamentales de la Unión Europea, permite una normativa de un Estado miembro, como la controvertida en el litigio principal, que confiere a los trabajadores por cuenta ajena con determinados tipos de discapacidad una protección especial ex ante frente al despido, sin conferir tal protección a los funcionarios con discapacidades del mismo tipo, a menos que se compruebe una vulneración del principio de igualdad de trato, lo cual ha de ser verificado por el órgano jurisdiccional remitente. A efectos de dicha verificación, la comparación de las situaciones debe basarse en un análisis centrado en el conjunto de las normas de derecho nacional pertinentes que regulan la posición de los trabajadores por cuenta ajena con una determinada discapacidad, por un lado, y de los funcionarios con la misma discapacidad, por otro, teniendo particularmente en cuenta el objetivo de la protección frente al despido controvertida en el litigio principal.

El TJUE recuerda que la circunstancia de que, con arreglo al art. 7, apdo. 2, de la Directiva 2000/78, los Estados miembros no tengan la obligación de mantener o adoptar medidas como las previstas en dicho precepto, sino que disponen de una facultad discrecional al respecto, no permite considerar que normas adoptadas por los Estados miembros como las controvertidas en el litigio principal queden fuera del ámbito de aplicación del derecho de la 
Unión. Cuando, a tenor de lo previsto en la normativa de la Unión, los Estados miembros pueden elegir entre varias formas de aplicación, deben ejercer su facultad discrecional observando los principios generales del derecho de la Unión, entre los que figura el principio de igualdad de trato. De ello se deduce que la normativa nacional aplicable en el litigio principal guarda relación con la aplicación del derecho de la Unión, lo cual implica que, en el caso de autos, resultan aplicables los principios generales del derecho de la Unión, concretamente el principio de igualdad de trato, y la Carta.

Una diferencia de trato está justificada cuando se basa en un criterio objetivo y razonable, es decir, cuando se relaciona con un fin legalmente admisible perseguido por la legislación en cuestión, y esta diferencia es proporcionada al objetivo perseguido por dicho trato. Por su parte, la exigencia del carácter análogo de las situaciones para determinar la existencia de una vulneración del principio de igualdad de trato debe apreciarse atendiendo a todos los aspectos que las caracterizan. Asimismo, no es necesario que las situaciones sean idénticas, sino que basta con que sean análogas y, por otro lado, que el examen del carácter análogo no debe efectuarse de manera global y abstracta, sino de un modo específico y concreto, teniendo en cuenta el objeto y la finalidad de la normativa nacional que establece la diferenciación controvertida. Por lo tanto, la comparación de las situaciones debe basarse en un análisis centrado en el conjunto de las normas de derecho nacional que regulan la posición de, por un lado, los trabajadores por cuenta ajena con una determinada discapacidad $y$, por otro, los funcionarios con la misma discapacidad, tal y como se desprende de la normativa interna pertinente aplicable al caso concreto, teniendo en cuenta el objetivo de la protección frente al despido controvertida en el litigio principal.

A este respecto el TJUE señala que el órgano jurisdiccional remitente, destacando el carácter específico de la protección prevista por el derecho búlgaro, observa que lo relevante de dicha protección consiste en que una entidad especializada evalúa las repercusiones del despido en el estado de salud de la persona afectada y decide si procede o no autorizarlo. Por lo tanto, la finalidad de una normativa como la controvertida en el litigio principal consiste en proteger al trabajador, no en función de cuál sea el vínculo jurídico constitutivo de su relación de trabajo, sino en función de su estado de salud. Por consiguiente, la distinción que opera dicha normativa entre los trabajadores por cuenta ajena con una determinada discapacidad y los funcionarios con la misma discapacidad no parece adecuada a la luz de la finalidad de dicha normativa, a mayor abundamiento cuando ambas categorías de personas con discapacidad pueden prestar servicios para la misma Administración. Corresponde al juez nacional verificar, en relación con la diferencia de trato alegada en el litigio principal, si la normativa nacional aplicable en su conjunto ofrece 
a los funcionarios con discapacidad un grado de protección equivalente al previsto por el mecanismo de la autorización previa de la Inspección de Trabajo con respecto a los trabajadores por cuenta ajena con discapacidad empleados como personal laboral en el sector público.

En el supuesto de que el art. 7, apdo. 2, de la Directiva 2000/78, a la luz de la Convención de las Naciones Unidas sobre los Derechos de las Personas con Discapacidad y atendiendo al principio general de igualdad de trato, se oponga a una normativa de un Estado miembro como la controvertida en el litigio principal, la obligación de respetar el derecho de la Unión exigirá extender el ámbito de aplicación de las normas nacionales que protegen a los trabajadores por cuenta ajena con un determinado tipo de discapacidad, con el fin de que dichas normas de protección cubran igualmente a los funcionarios con una discapacidad del mismo tipo.

Una norma interna de una empresa que prohíbe el uso visible de cualquier signo político, filosófico o religioso no constituye una discriminación directa, pero, en ausencia de tal norma, la voluntad de un empresario de tener en cuenta los deseos de un cliente de que los servicios de dicho empresario no sigan siendo prestados por una trabajadora que lleva un pañuelo islámico no puede considerarse un requisito profesional que permita descartar la existencia de una discriminación (Sentencias de 14 de marzo de 2017, G4S Secure Solutions, C-157/15, EU:C:2017:203, y Bougnaoui, C-188/15, EU:C:2017:204).

En el asunto G4S Secure Solutions, la Sra. Achbita comunicó a su empleador que tenía la intención de llevar un pañuelo islámico durante las horas de trabajo. El comité de empresa de G4S aprobó una modificación del reglamento interno, con el siguiente tenor: «Se prohíbe a los trabajadores llevar signos visibles de sus convicciones políticas, filosóficas o religiosas u observar cualquier rito derivado de estas en el lugar de trabajo». En razón de la persistente voluntad de la Sra. Achbita de llevar el pañuelo islámico en su lugar de trabajo, esta fue despedida. La Sra. Achbita impugnó el despido ante los órganos jurisdiccionales belgas.

El TJUE empieza recordando que la Directiva 2000/78/CE del Consejo, relativa al establecimiento de un marco general para la igualdad de trato en el empleo y la ocupación, entiende por "principio de igualdad de trato» la ausencia de toda discriminación directa o indirecta basada, entre otros motivos, en la religión. Aunque la Directiva no define el concepto de «religión», el legislador de la Unión se ha remitido al CEDH y a las tradiciones constitucionales comunes a los Estados miembros, reafirmadas en la Carta de los Derechos Fundamentales de la Unión Europea. Por consiguiente, debe interpretarse que 
el concepto de «religión» cubre tanto el hecho de tener convicciones religiosas como la libertad de las personas de manifestar públicamente dichas convicciones.

El TJUE observa que la norma interna de G4S tiene por objeto el uso de signos visibles de convicciones políticas, filosóficas o religiosas y, por ende, atañe indistintamente a cualquier manifestación de tales convicciones. Por consiguiente, dicha norma trata por igual a todos los trabajadores de la empresa, ya que les impone en particular, de forma general e indiferenciada, una neutralidad indumentaria. De los autos que obraban en poder del TJUE no se desprendía que esta norma interna se hubiera aplicado a la Sra. Achbita de forma diferente a los demás trabajadores de G4S. En consecuencia, tal norma interna no establece una diferencia de trato basada directamente en la religión o las convicciones en el sentido de la Directiva, contraria al art. 2, apdo. 2, letra a), de la Directiva 2000/78/CE del Consejo, relativa al establecimiento de un marco general para la igualdad de trato en el empleo y la ocupación.

El TJUE señala que, sin embargo, no puede descartarse que el juez nacional llegue a la conclusión de que la norma interna establece una diferencia de trato basada indirectamente en la religión o las convicciones (en el sentido del art. 2, apdo. 2, letra b), de la Directiva 2000/78) si se acredita que la obligación aparentemente neutra que contiene dicha norma ocasiona, de hecho, una desventaja particular a aquellas personas que profesan una religión o tienen unas convicciones determinadas. No obstante, tal diferencia de trato no constituirá una discriminación indirecta si puede justificarse objetivamente con una finalidad legítima y si los medios para la consecución de esta finalidad son adecuados y necesarios. Tras subrayar que el juez nacional que conoce del litigio es el único competente para determinar si, y en qué medida, la norma interna es conforme con estos requisitos, el TJUE da indicaciones al respecto.

Señala que el deseo de un empresario de ofrecer una imagen neutra ante sus clientes tanto del sector público como del sector privado tiene un carácter legítimo, en particular cuando solo atañe a los trabajadores que están en contacto con los clientes, ya que dicho deseo está vinculado a la libertad de empresa, reconocida en la Carta. Además, la prohibición del uso visible de signos de convicciones políticas, filosóficas o religiosas es apta para garantizar la correcta aplicación de un régimen de neutralidad, siempre que dicho régimen se persiga realmente de forma congruente y sistemática. A este respecto, corresponderá al juez nacional comprobar si G4S había establecido, con anterioridad al despido de la Sra. Achbita, un régimen general e indiferenciado en la materia. En el caso de autos, procederá comprobar igualmente si la prohibición atañe únicamente a los trabajadores de G4S que están en contacto con los clientes. En tal caso, la prohibición deberá considerarse estrictamente necesaria para alcanzar la meta perseguida. También cabrá comprobar si, te- 
niendo en cuenta las limitaciones propias de la empresa y sin que ello representara una carga adicional para esta, G4S tenía la posibilidad de ofrecer a la Sra. Achbita un puesto de trabajo que no conllevara un contacto visual con los clientes en lugar de proceder a su despido.

No obstante, en el asunto Bougnaoui y $A D D H$, el TJUE interpreta el art. 4, apdo. 1, de la Directiva 2000/78/CE, en el sentido de que la voluntad de un empresario de tener en cuenta los deseos de un cliente de que los servicios de dicho empresario no sigan siendo prestados por una trabajadora que lleva un pañuelo islámico no puede considerarse un requisito profesional esencial y determinante en el sentido de esta disposición

Tras un período de prácticas, Micropole contrató a la Sra. Bougnaoui por tiempo indefinido como ingeniero de proyectos. Tras la queja de un cliente a cuyo centro de trabajo Micropole había enviado a la Sra. Bougnaoui, esta empresa reiteró el principio de necesaria neutralidad ante los clientes y pidió a la Sra. Bougnaoui que dejara de llevar el velo. Esta se negó y fue despedida posteriormente. La Sra. Bougnaoui impugnó el despido ante los órganos jurisdiccionales franceses.

En su sentencia el TJUE empieza indicando que la resolución de remisión no permite saber si la cuestión prejudicial planteada por el Tribunal de Casación francés reposa en la observación de una diferencia de trato basada directa o indirectamente en la religión o las convicciones.

Por consiguiente, corresponderá al Tribunal de Casación francés comprobar si el despido de la Sra. Bougnaoui se fundó en el incumplimiento de una norma interna que prohibía el uso visible de signos de convicciones políticas, filosóficas o religiosas. En tal caso, incumbirá a dicho Tribunal comprobar si concurren los requisitos mencionados en la sentencia G4S Secure Solutions, a saber, si la diferencia de trato dimanante de una norma aparentemente neutra que puede ocasionar, de hecho, una desventaja particular a determinadas personas, está justificada objetivamente con la finalidad de seguir un régimen de neutralidad y si los medios para alcanzar dicha finalidad son adecuados y necesarios.

En cambio, si el despido de la Sra. Bougnaoui no se basó en la existencia de tal norma interna, cabrá determinar si la voluntad de un empresario de tener en cuenta los deseos de un cliente de que los servicios de dicho empresario no sigan siendo prestados por una trabajadora que lleva un pañuelo islámico está justificada en el sentido del art. 4, apdo. 1, de la Directiva, según el cual los Estados miembros pueden disponer que una diferencia de trato prohibida por la Directiva no tenga carácter discriminatorio cuando, debido a la naturaleza de una actividad profesional o al contexto en que esta se lleve a cabo, la característica de que se trate constituya un requisito profesional esencial y 
determinante, siempre y cuando el objetivo sea legítimo y el requisito proporcionado.

A este respecto, el TJUE recuerda que solo en muy contadas circunstancias una característica vinculada en particular a la religión puede constituir un requisito profesional esencial y determinante, ya que este concepto implica un requisito objetivamente dictado por la naturaleza de una actividad profesional o por el contexto en que esta se lleve a cabo y no cubre consideraciones subjetivas, como la voluntad del empresario de tener en cuenta los deseos particulares del cliente.

\section{JUSTICIA, LIBERTAD Y SEGURIDAD}

Los Estados miembros no están obligados, en virtud del derecho de la Unión, a expedir un visado humanitario a las personas que deseen entrar en su territorio con la intención de pedir asilo, pero son libres de hacerlo sobre la base de su derecho nacional (Sentencia de 7 de marzo de 2017, X y X, C-638/16 PPU, EU:C:2017:173).

Una pareja siria y sus tres hijos menores, que viven todos en Alepo (Siria), presentaron unas solicitudes de visados humanitarios en la embajada de Bélgica en Beirut (Líbano), antes de regresar a Siria al día siguiente. Con estas solicitudes pretendían obtener visados de validez territorial limitada, sobre la base del Reglamento (CE) 810/2009 del Parlamento Europeo y del Consejo, por el que se establece un Código Comunitario sobre Visados (CV), para poder abandonar la ciudad asediada de Alepo y presentar una petición de asilo en Bélgica.

Las autoridades belgas desestimaron esas solicitudes. Consideraban que, al solicitar un visado de validez territorial limitada para presentar una solicitud de asilo en Bélgica, la familia siria en cuestión tenía manifiestamente la intención de permanecer más de noventa días en Bélgica, lo cual es contrario al CV de la UE. Además, insistían en que autorizar la expedición de un visado de entrada a esta familia para que pueda presentar una solicitud de asilo en Bélgica equivaldría a permitirle presentar una solicitud de asilo en una representación diplomática.

La familia siria impugnó la decisión denegatoria sosteniendo que la Carta de los Derechos Fundamentales de la UE y el CEDH imponen a los Estados miembros la obligación positiva de garantizar el derecho de asilo. La concesión de la protección internacional sería el único medio para evitar el riesgo de que se incumpla la prohibición de la tortura y de las penas o los tratos inhumanos o degradantes. 
El TJUE señala en su sentencia, en primer lugar, que el CV fue adoptado sobre la base del art. 62, punto 2, letras a) y b), inciso ii), del Tratado $\mathrm{CE}$, en virtud del cual el Consejo adopta las medidas relativas a los visados aplicables a las estancias cuya duración no supere los tres meses, que incluyen los procedimientos y las condiciones para la expedición de visados por los Estados miembros. A tenor del art. $1 \mathrm{del} \mathrm{CV}$, este tiene por objeto establecer los procedimientos y las condiciones para la expedición de visados para tránsito o estancias previstas en el territorio de los Estados miembros no superiores a noventa días por período de ciento ochenta días. El art. 2, punto 2, letras a) y b), de este código define el concepto de "visado», como «la autorización expedida por un Estado miembro», respectivamente, a efectos del «tránsito por el territorio de los Estados miembros o estancias en dicho territorio cuya duración prevista no sea superior a 90 días por período de 180 días» y del «tránsito por las zonas internacionales de tránsito de los aeropuertos de los Estados miembros». Pues bien, los demandantes en el litigio principal presentaron en la embajada de Bélgica en Líbano, basándose en el art. 25 del CV, solicitudes de visado por razones humanitarias con la intención de pedir asilo en Bélgica en cuanto llegaran a dicho Estado miembro y, por ende, de obtener un permiso de residencia cuya validez no estuviera limitada a noventa días.

En la medida en que el legislador de la Unión no ha adoptado hasta la fecha ningún acto sobre la base del art. 79 TFUE, apdo. 2, letra a), con respecto a las condiciones en las cuales los Estados miembros expedirán visados o permisos de residencia de larga duración a los nacionales de terceros países por razones humanitarias, las solicitudes controvertidas en el litigio principal solo están sujetas al derecho nacional. En consecuencia, dado que la situación controvertida en el litigio principal no está regulada por el derecho de la Unión, no le resultan aplicables las disposiciones de la Carta ni, en particular, las de sus arts. 4 y 18.

Añade que la conclusión contraria equivaldría a permitir a los nacionales de terceros países que presenten solicitudes de visado, basándose en dicho código, con la finalidad de obtener la protección internacional en el Estado miembro de su elección, lo cual iría en contra de la estructura general del sistema establecido por el Reglamento (UE) 604/2013 del Parlamento Europeo y del Consejo, por el que se establecen los criterios y mecanismos de determinación del Estado miembro responsable del examen de una solicitud de protección internacional presentada en uno de los Estados miembros por un nacional de un tercer país o un apátrida. Tal conclusión contraria equivaldría a obligar a los Estados miembros, en virtud del CV, a permitir, en la práctica, a los nacionales de terceros países que presenten una solicitud de protección internacional en las representaciones de los Estados miembros situadas en el territorio de un tercer país. Teniendo en cuenta que el CV no tiene como fina- 
lidad armonizar la normativa de los Estados miembros relativa a la protección internacional, consta que los actos de la Unión adoptados sobre la base del art. 78 TFUE por los que se regulan los procedimientos aplicables a las solicitudes de protección internacional no prevén tal obligación y, al contrario, excluyen de su ámbito de aplicación las solicitudes presentadas en las representaciones de los Estados miembros. Así, resulta del art. 3, apdos. 1 y 2, de la Directiva 2013/32/UE del Parlamento Europeo y del Consejo, sobre procedimientos comunes para la concesión o la retirada de la protección internacional, que esta Directiva es aplicable a las solicitudes de protección internacional presentadas en el territorio, incluida la frontera, en las aguas territoriales o en las zonas de tránsito de los Estados miembros, pero no a las solicitudes de asilo diplomático o territorial presentadas en las representaciones de los Estados miembros. Asimismo, de los arts. 1 y 3 del Reglamento 604/2013 se desprende que los Estados miembros solo están obligados a examinar cualquier solicitud de protección internacional presentada en el territorio de un Estado miembro, incluida la frontera, o en las zonas de tránsito, y que los procedimientos establecidos en ese reglamento se aplican únicamente a tales solicitudes de protección internacional.

Puede denegarse una solicitud de asilo cuando el solicitante haya participado en las actividades de una red terrorista, sin que sea necesario que el solicitante de asilo haya cometido personalmente actos de terrorismo ni que haya incitado a su comisión o haya participado en ellos (Sentencia de 31 de enero de 2017, Louani, C-573/14, EU:C:2017:71).

El Sr. Lounani, de nacionalidad marroquí, fue condenado a una pena de prisión de seis años por participación en las actividades de un grupo terrorista —la célula belga del Grupo Islámico Combatiente Marroquí (GICM) como miembro dirigente, así como por asociación ilícita, falsificación y uso de documentos falsos y estancia ilegal. Entre otras cosas, se consideró culpable a Mostafa Lounani de "participación activa en la organización de una red de envío de voluntarios a Irak». En particular, la transmisión fraudulenta de pasaporte se calificó de «acto de participación en la actividad de una célula que aporta su apoyo logístico a un movimiento terrorista».

El Sr. Lounani presentó una solicitud de asilo a las autoridades belgas, invocando el temor a ser perseguido de ser devuelto a su país de origen, dado que, como consecuencia de su condena en Bélgica, las autoridades marroquíes podían considerarlo como un islamista radical y yihadista. Esta solicitud de asilo fue denegada. Siguió un contencioso complejo ante las autoridades judiciales belgas, que llegó a su Consejo de Estado, quién decidió plantear al TJUE una serie de cuestiones prejudiciales. Esencialmente, preguntaba cuáles 
son las condiciones en las que puede excluirse a un solicitante del estatuto de refugiado por «actos contrarios a las finalidades y a los principios de las $\mathrm{Na}$ ciones Unidas», cuando haya sido condenado por participar en las actividades de un grupo terrorista, sin haber cometido personalmente ningún acto de terrorismo.

El TJUE subraya, en particular, que en la Resolución 2178 (2014), el Consejo de Seguridad expresó su "grave preocupación por la grave y creciente amenaza que plantean los combatientes terroristas extranjeros» y manifestó su inquietud por las redes organizadas por las organizaciones terroristas a través de las cuales se mueven en una y otra dirección los combatientes terroristas extranjeros y los recursos para apoyarlos. Por lo tanto, la aplicación de la exclusión del estatuto de refugiado prevista en el art. 12, apdo. 2, letra c), de la Directiva 2004/83/CE del Consejo, por la que se establecen normas mínimas relativas a los requisitos para el reconocimiento y el estatuto de nacionales de terceros países o apátridas como refugiados o personas que necesitan otro tipo de protección internacional y al contenido de la protección concedida, no puede limitarse a quienes hayan cometido efectivamente actos de terrorismo, sino que puede extenderse también a quienes realicen actividades de reclutamiento, organización, transporte o equipamiento de las personas que viajan a un Estado distinto de sus Estados de residencia o nacionalidad para cometer, planificar o preparar actos terroristas.

El TJUE recuerda que la evaluación final de la solicitud de protección internacional incumbe a las autoridades nacionales competentes, con el control del juez nacional. Sin embargo, señala, entre los factores que deben tenerse en cuenta, que el Sr. Lounani, según las propias apreciaciones del Conseil d'État, era miembro dirigente de un grupo terrorista de dimensión internacional que en 2002 había sido incluido en la lista de las Naciones Unidas que identifica los individuos y entidades sujetos a sanción y que ha permanecido en esta lista, posteriormente actualizada. Las actividades del Sr. Lounani de apoyo logístico a las actividades de este grupo tienen una dimensión internacional, dado que estuvo implicado en la falsificación de pasaportes y prestó apoyo a voluntarios para viajar a Irak. Según el TJUE, estos actos pueden justificar la exclusión del estatuto de refugiado. Por otro lado, la circunstancia de que el Sr. Lounani haya sido condenado por participación en las actividades de un grupo terrorista y de que esa condena haya adquirido firmeza tiene especial relevancia, en el marco de la evaluación individual que debe efectuar la autoridad competente.

Por todo ello interpreta el art. 12, apdo. 2, letra c), y el art. 12, apdo. 3, de la Directiva 2004/83 en el sentido de que pueden justificar la exclusión del estatuto de refugiado actos de participación en una organización terrorista como los que motivaron la condena del recurrido en el litigio principal, aun 
cuando no se haya demostrado que la persona de que se trate haya cometido un acto de terrorismo, tal como se precisa en las resoluciones del Consejo de Seguridad de las Naciones Unidas, ni haya intentado cometerlo o amenazado con hacerlo. A efectos de la evaluación individual de los hechos para apreciar si hay razones fundadas para considerar que una persona es culpable de actos contrarios a las finalidades y a los principios de las Naciones Unidas, ha incitado a la comisión de tales actos o ha participado en ellos, la circunstancia de que haya sido condenada por los tribunales de un Estado miembro por su participación en las actividades de un grupo terrorista tiene especial relevancia, así como el hecho de que haya sido miembro dirigente de ese grupo, sin que sea necesario demostrar que haya incitado personalmente a la comisión de un acto de terrorismo o haya participado en él.

En caso de que se acredite un supuesto de fuerza mayor, las autoridades encargadas de ejecutar una orden de detención europea deberán fijar una tercera fecha de entrega cuando los dos primeros intentos de entrega hayan fracasado debido a la resistencia opuesta por la persona buscada (Sentencia de 25 de enero de 2017, Vilkas, C-640/15, EU:C:2017:39).

Un tribunal lituano dictó contra el Sr. Tomas Vilkas dos órdenes de detención europeas. Debido a la resistencia que puso, no fue posible la entrega del Sr. Vilkas a las autoridades lituanas utilizando un vuelo comercial. El ministro irlandés de Justicia e Igualdad presentó entonces ante la High Court (Tribunal Superior de Irlanda) una solicitud de autorización de un tercer intento de entrega del Sr. Vilkas. Sin embargo, dicho tribunal consideró que no era competente para pronunciarse sobre esa solicitud y ordenó la liberación del Sr. Vilkas. En estas circunstancias, el juez remitente preguntaba al TJUE si el derecho de la Unión permite a las autoridades acordar una nueva fecha de entrega en más de una ocasión cuando se produzca un supuesto de fuerza mayor y, en su caso, en qué circunstancias.

El TJUE debe interpretar el art. 23, apdo. 3, de la Decisión Marco 2002/584/JAI del Consejo, relativa a la orden de detención europea y a los procedimientos de entrega entre Estados miembros, en su versión modificada. De entrada, el TJUE recuerda que, en virtud del derecho de la Unión, la persona buscada será entregada a más tardar diez días después de la decisión definitiva sobre la ejecución de la orden de detención europea. Sin embargo, esta norma está sujeta a algunas excepciones. Así, se establece que, si la entrega de la persona buscada en el plazo previsto resulta imposible debido a cualquier circunstancia ajena al control de alguno de los Estados miembros afectados, las autoridades judiciales podrán acordar una nueva fecha de entrega. Basándose principalmente en los objetivos perseguidos por el legislador de la Unión, el 
TJUE concluye que el derecho de la Unión no limita expresamente el número de nuevas fechas de entrega y permite fijar una nueva fecha de entrega cuando la entrega haya fracasado más de diez días después de la decisión definitiva sobre la ejecución de la orden de detención europea.

A continuación, el TJUE examina si la autoridad judicial de ejecución (en este caso, las autoridades irlandesas) y la autoridad judicial emisora (en este caso, las autoridades lituanas) deben acordar una nueva fecha de entrega si la resistencia opuesta de manera reiterada por la persona buscada ha impedido dos veces la entrega.

En primer lugar, el TJUE considera que el legislador de la Unión tuvo la intención de referirse al concepto de fuerza mayor entendido en el sentido de circunstancias anormales, imprevisibles y ajenas a quien lo invoca, cuyas consecuencias no habrían podido evitarse a pesar de toda la diligencia empleada.

En segundo lugar, el TJUE señala que el concepto de fuerza mayor debe interpretarse de manera estricta. En efecto, un supuesto de fuerza mayor únicamente puede justificar la prórroga del plazo de entrega de la persona buscada en la medida en que la entrega en el plazo previsto resulte «imposible»; la circunstancia de que la entrega resulte más difícil no puede, por tanto, justificar la aplicación de la norma. El TJUE concluye que, en este contexto, la resistencia opuesta por una persona buscada a su entrega puede considerarse válidamente una circunstancia ajena y anormal. En cambio, esta situación no puede, en principio, calificarse de circunstancia imprevisible. Con mayor razón, en una situación en la que la persona buscada ya se opuso a un primer intento de entrega, el hecho de que se resista también a un segundo intento normalmente no puede considerarse imprevisible.

El TJUE indica que las autoridades estatales disponen de medios que les permiten, en la mayoría de los casos, vencer la resistencia opuesta por la persona buscada. También es posible plantearse recurrir a medios de transporte cuya utilización no podrá impedir de manera eficaz la resistencia de la persona buscada.

Sin embargo, el TJUE estima que no cabe excluir completamente que, debido a circunstancias excepcionales, la resistencia opuesta por la persona buscada a su entrega no pueda objetivamente ser prevista por las autoridades implicadas y que las consecuencias de dicha resistencia para la entrega no puedan evitarse a pesar de toda la diligencia empleada por dichas autoridades. El TJUE concluye que corresponde al órgano jurisdiccional remitente comprobar si se ha demostrado la existencia de tales circunstancias en el presente asunto.

Por otra parte, el TJUE precisa que el art. 15, apdo. 1, y el art. 23 de la Decisión Marco 2002/584, en su versión modificada por la Decisión Marco 2009/299, no pueden interpretarse en el sentido de que implique que, una vez 
expirados los plazos previstos, la autoridad judicial de ejecución ya no puede acordar una nueva fecha de entrega con la autoridad judicial emisora o que el Estado miembro de ejecución ya no está obligado a proseguir el procedimiento de ejecución. Una interpretación en el sentido de que la autoridad judicial de ejecución ya no debe efectuar la entrega de la persona buscada ni acordar, para ello, una nueva fecha de entrega con la autoridad judicial emisora tras la expiración de los plazos previstos menoscabaría el objetivo de aceleración y simplificación de la cooperación judicial. Por lo tanto, la mera expiración de los plazos previstos no exime al Estado miembro de ejecución de su obligación de proseguir el procedimiento de ejecución de la orden de detención europea y de efectuar la entrega de la persona buscada, y las autoridades implicadas deben acordar para ello una nueva fecha de entrega.

Las autoridades nacionales pueden denegar, por motivos de seguridad pública, la concesión a una ciudadana iraní titulada en una universidad sometida a medidas restrictivas de un visado a efectos de estudios en un ámbito sensible tal como la seguridad de la tecnología de la información (Sentencia de 4 de abril de 2017, Fahimian, C-544/15, EU:C:2017:255).

La Sra. Sahar Fahimian, ciudadana iraní, posee un máster universitario en Tecnología de la Información, expedido por la Sharif University of Technology (Irán). Esta universidad está sometida a medidas restrictivas por parte de la Unión Europea en razón del apoyo que presta al Gobierno iraní, especialmente en el ámbito militar. La Sra. Fahimian obtuvo una beca para estudiar en Alemania estudios doctorales, y presentó posteriormente en la embajada alemana en Teherán una solicitud de visado a efectos de estudios. Tras serle denegado el visado, interpuso un recurso contencioso-administrativo. El Gobierno alemán justificaba la denegación por el temor de que los conocimientos que la Sra. Fahimian adquiera durante su investigación puedan emplearse más adelante con fines abusivos en Irán (como la obtención de información confidencial de los países occidentales, la represión interna o, en general, en relación con violaciones de los derechos humanos).

En este contexto, se solicitó al TJUE que interpretara la Directiva 2004/114/CE del Consejo, relativa a los requisitos de admisión de los nacionales de terceros países a efectos de estudios, intercambio de alumnos, prácticas no remuneradas o servicios de voluntariado. Esta directiva tiene por finalidad promover Europa como centro mundial de excelencia de la enseñanza y de la formación profesional favoreciendo la movilidad de los estudiantes nacionales de terceros países que tengan la intención de cursar estudios en la Unión. Sin 
embargo, para conceder un visado a tal efecto, la Directiva exige en particular que el solicitante no sea considerado una amenaza para la seguridad pública.

En su sentencia el TJUE responde que el art. 6, apdo. 1, letra d) de la Directiva debe interpretarse en el sentido de que las autoridades nacionales disponen de un amplio margen de apreciación de los hechos para comprobar, a la luz del conjunto de elementos pertinentes que caractericen la situación de un nacional de un tercer país que solicita un visado a efectos de estudios, si dicho nacional representa una amenaza, siquiera potencial, para la seguridad pública.

Además, la Directiva no se opone a que se deniegue un visado a efectos de estudios a un nacional de un tercer país que a) está titulado en una universidad sometida a medidas restrictivas de la Unión —en razón del importante historial de relaciones de aquélla con el Gobierno iraní en ámbitos militares o relacionados con éstos_- y b) pretende llevar a cabo en el Estado miembro de que se trata una investigación en un ámbito sensible para la seguridad pública, si los elementos de que disponen las autoridades nacionales competentes permiten temer que los conocimientos que adquiera esa persona en el curso de su investigación pueden utilizarse posteriormente con fines contrarios a la seguridad pública. A este respecto, el TJUE puntualiza que la obtención de información confidencial de países occidentales, la represión interna o, en general, las violaciones de los derechos humanos son fines contrarios a la salvaguardia de la seguridad pública. En estas circunstancias, corresponderá al juez nacional comprobar que la decisión de denegación de la solicitud de la Sra. Fahimian se funde en razones debidamente motivadas y en una base fáctica suficientemente sólida.

\section{RELACIONES EXTERIORES}

El TJUE confirma la validez de las medidas restrictivas adoptadas por el Consejo en el contexto de la crisis ucraniana frente a determinadas empresas rusas, incluida la sociedad Rosneft (Sentencia de 28 de marzo de 2017, Rosneft, C-72/15, EU:C:2017:236).

Mediante Decisión 2014/512/PESC y el Reglamento 833/2014, de la misma fecha, mediante los cuales el Consejo adoptó medidas restrictivas en respuesta a las acciones de Rusia destinadas a desestabilizar la situación de Ucrania, se imponen medidas y limitaciones a determinadas operaciones financieras y a la exportación de determinados productos y tecnologías sensibles, se restringe el acceso de determinadas entidades rusas al mercado de capital y se prohíbe que se presten servicios que son necesarios para determi- 
nadas operaciones petrolíferas. El fin de las medidas adoptadas por el Consejo es aumentar el coste de las acciones emprendidas por Rusia frente a la soberanía de Ucrania. Una de las sociedades que son objeto de las medidas es la rusa Rosneft, especializada en el sector petrolífero y gasístico. Ante el Tribunal Superior de Justicia del Reino Unido (High Court of Justice, England and Wales) Rosneft ponía en entredicho que fueran válidas a la luz del derecho de la Unión tanto las medidas restrictivas adoptadas por el Consejo frente a dicha sociedad.

Por lo que se refiere a las medidas adoptadas por el Reino Unido, el órgano jurisdiccional remitente se planteaba en particular, por una parte, si en caso de infracción de las medidas restrictivas el Estado miembro podía imponer sanciones penales antes de que el TJUE precisara el sentido de los términos empleados por el Consejo y, por otra, si las medidas restrictivas alcanzan al procesamiento de pagos por parte de los bancos y prohíben la emisión de certificados internacionales de títulos que representen acciones emitidas antes de la adopción de las medidas.

Tras confirmar el TJUE su competencia para conocer de la validez de los actos en cuestión (véase supra) el TJUE declara que no hay ningún aspecto que afecte a la validez de la Decisión ni del Reglamento. En concreto el TJUE considera que la circunstancia de que la Decisión predetermine parte del contenido del Reglamento y que precise el objeto de las medidas restrictivas no menoscaba el ejercicio de las competencias atribuidas a la Alta Representante de la Unión para Asuntos Exteriores y Política de Seguridad y a la Comisión.

Señala además que el Acuerdo de Colaboración y Cooperación entre la Unión Europea y Rusia (ACCUER) no obsta a la adopción de dichos actos. El TJUE no descarta que el acuerdo mencionado recoja disposiciones que puedan ser invocadas por un justiciable ante un órgano jurisdiccional nacional, sin que se exija a tal fin la adopción de medidas de aplicación complementarias. No obstante, declarar que, aun admitiendo que las medidas restrictivas controvertidas en el litigio principal no fueran conformes con determinadas disposiciones del referido acuerdo, su art. 99 permite la adopción de las mismas. A tenor del mismo, nada de lo dispuesto en este acuerdo será obstáculo para que cualquiera de las partes contratantes adopte medidas que estime necesarias para la protección de los intereses que considere esenciales para su propia seguridad, en particular en tiempo de guerra o de grave tensión internacional que constituya una amenaza de guerra, o con el fin de cumplir las obligaciones que haya aceptado a efectos de mantener la paz y la seguridad internacionales. La redacción de esa disposición no exige que la "guerra» o la "grave tensión internacional que constituya una amenaza de guerra» se refieran a un conflicto armado que involucre directamente al territorio de la Unión. Así pues, los acontecimientos que se produzcan en un país vecino de la 
Unión, como es el caso de lo sucedido en Ucrania, que dio lugar a las medidas restrictivas controvertidas en el litigio principal, pueden justificar la adopción de medidas cuyo objeto sea proteger los intereses esenciales para la seguridad de la Unión y salvaguardar la paz y seguridad internacionales, de conformidad con el objetivo atribuido, a tenor del art. 21 TUE, apdos. 1, párr. primero, y 2, letra c), a la acción exterior de aquella, siempre dentro del respeto a los principios y propósitos de la Carta de las Naciones Unidas.

El Consejo goza de una amplia facultad de apreciación en los ámbitos que impliquen por su parte opciones de naturaleza política, económica y social y en los que deba realizar apreciaciones complejas. Los considerandos de los actos impugnados apuntan a que las medidas restrictivas enumeradas en los actos controvertidos tenían por objeto promover una solución pacífica de la crisis ucraniana. Dicha finalidad concuerda con la de salvaguardar la paz y seguridad internacionales, de conformidad con los objetivos de la acción exterior de la Unión establecidos en el art. 21 TUE. En estas circunstancias, y por mor de la amplia facultad de apreciación con que cuenta en este ámbito, el Consejo pudo estimar que, a efectos del art. 99 del ACCUER, la adopción de las medidas controvertidas en el litigio principal era necesaria para proteger los intereses esenciales para la seguridad de la Unión y para salvaguardar la paz y seguridad internacionales.

Asimismo, el Consejo motivó suficientemente los actos. El TJUE declara que la importancia de los objetivos que persiguen los actos controvertidos puede justificar las consecuencias negativas que se derivan para determinados actores económicos. Habida cuenta en especial de la evolución progresiva de la intensidad de las medidas restrictivas adoptadas en respuesta a la crisis ucraniana, debe considerase que la injerencia en la libertad de empresa y el derecho de propiedad de Rosneft no resulta desproporcionada.

El TJUE considera por otra parte que los términos del Reglamento no obstan a que un Estado miembro imponga sanciones penales que sean de aplicación en caso de infracción de lo dispuesto en el propio Reglamento. La posibilidad de que los términos usados en el Reglamento sean objeto de una clarificación gradual posterior por parte del TJUE no impide que un Estado miembro pueda adoptar sanciones para garantizar la aplicación efectiva del mismo.

El TJUE declara que las medidas restrictivas no alcanzan al procesamiento de pagos por parte de los bancos, señalando que el legislador de la Unión habría empleado otra expresión distinta que «asistencia financiera» si hubiera querido supeditar el procesamiento de cualquier transferencia bancaria a una solicitud adicional de autorización, habida cuenta de que los servicios de pagos los prestan entidades financieras en condición de intermediario, sin que ello suponga la movilización de fondos propios; por otra parte, el TJUE señala 
en ese contexto que el Reglamento no tiene por objeto instaurar una inmovilización de activos ni restricciones en materia de transferencia de fondos.

Por último, el TJUE declara que las medidas prohíben la emisión de certificados internacionales representativos de acciones emitidas a su vez antes de la adopción de las medidas mismas.

Las actividades de fuerzas armadas en período de conflicto armado, en el sentido del derecho internacional humanitario, pueden constituir «actos terroristas» a los efectos de adoptar medidas restrictivas (Sentencia de 14 de marzo de 2017, $A$, C-158/14, EU:C:2017:202).

Según las autoridades neerlandesas, A, B, C y D realizaron captación de fondos para los Liberation Tigers of Tamil Eelam (Tigres de Liberación de Eelam Tamil, LTTE), una organización que se enfrentó en una guerra civil contra el Gobierno de Sri Lanka para crear un Estado independiente en el norte y el este de Sri Lanka para el pueblo tamil, y que es clasificada como «terrorista» por la Unión Europea desde hace más de diez años. En virtud de la normativa neerlandesa que aplica la resolución 1373 (2001) del Consejo de Seguridad de las Naciones Unidas, las autoridades neerlandesas incluyeron a A, B, C y D entre las personas sujetas a medidas restrictivas con el fin de luchar contra el terrorismo. Por consiguiente, se procedió a la congelación de sus fondos financieros. En este marco, las autoridades neerlandesas calificaron a los LTTE como organización terrorista. A tales efectos se tomaba en consideración el Reglamento de Ejecución (UE) 610/2010 del Consejo, que mantenía a los LTTE en una lista de grupos implicados en actos terroristas y sujetos a medidas restrictivas.

En sus recursos ante los órganos jurisdiccionales neerlandeses, A, B, C y $\mathrm{D}$ alegaron que dicho reglamento era inválido ya que las actividades de los LTTE no constituían actos terroristas. Arguyeron, en cambio, que los LTTE eran una fuerza armada no estatal que participó en un conflicto armado sin carácter internacional en Sri Lanka, por lo que sus acciones se regían exclusivamente por el derecho internacional humanitario, no por la legislación de la Unión ni por las normas internacionales en materia de lucha contra el terrorismo.

El tribunal remitente preguntaba, en esencia, al TJUE si la inclusión, mediante el Reglamento de Ejecución 610/2010 y mediante los actos de la Unión anteriores a ese reglamento, de la organización LTTE en la lista de congelación de fondos es válida. Pedía que se dilucide, en particular, si las actividades de una fuerza armada en período de conflicto armado, en el sentido del derecho internacional humanitario, pueden constituir "delitos de terrorismo", en el sentido de la Decisión Marco 2002/475/JAI del Consejo, sobre la lucha 
contra el terrorismo, o «actos terroristas», en el sentido de la Posición Común 2001/931/PESC del Consejo, sobre la aplicación de medidas específicas de lucha contra el terrorismo, y del Reglamento (CE) 2580/2001 del Consejo, sobre medidas restrictivas específicas dirigidas a determinadas personas y entidades con el fin de luchar contra el terrorismo.

El órgano jurisdiccional remitente se refería en particular a la Decisión Marco 2002/475 que, como precisa su considerando 11, no rige las actividades de una fuerza armada en período de conflicto armado. El TJUE recuerda que la Decisión Marco 2002/475 tiene por objeto la aproximación de la definición de delitos de terrorismo en todos los Estados miembros, la previsión de penas y sanciones acordes con la gravedad de los mismos y el establecimiento de normas sobre competencia para garantizar que puedan emprenderse acciones judiciales eficaces contra cualquier delito de terrorismo. En este contexto de derecho punitivo se inscribe el considerando 11 de la Decisión Marco 2002/475, según el cual esta no rige las actividades de las fuerzas armadas en período de conflicto armado, en el sentido dado a estos términos en derecho internacional humanitario, ni las actividades de las fuerzas armadas de un Estado en el ejercicio de sus funciones oficiales, en la medida en que se rigen por otras normas de derecho internacional.

En cambio, por lo que concierne a la Posición Común 2001/931 y al Reglamento 2580/2001, su objeto es la aplicación de la Resolución 1373 (2001), adoptada tras los ataques terroristas perpetrados en los Estados Unidos el 11 de septiembre de 2001, y se dirige principalmente a la prevención de actos terroristas mediante la adopción de medidas de congelación de fondos para obstaculizar los actos preparatorios de tales actos, como la financiación de personas o entidades que puedan perpetrar actos terroristas. La designación de las personas y de las entidades que deben figurar en la lista prevista en el art. 2, apdo. 3, del Reglamento 2580/2001 no constituye, en este contexto, una sanción, sino una medida preventiva adoptada según un sistema a dos niveles, en el sentido de que, según el art. 1, apdo. 4, de la Posición Común 2001/931, el Consejo solo puede incluir en dicha lista personas y entidades en relación con las cuales existe una decisión adoptada por una autoridad competente, ya sea la apertura de investigaciones o de procedimientos, basados en pruebas o en indicios serios y creíbles, en relación con la comisión de un acto terrorista o la tentativa de cometerlo, la participación en él o su facilitación, ya sea una condena por dichos hechos. Por ello, el considerando 11 de la Decisión Marco 2002/475 no es pertinente para interpretar el concepto de «actos terroristas», en el sentido de la Posición Común 2001/931 y del Reglamento 2580/2001.

El tribunal remitente estimaba que diversos convenios internacionales pueden interpretarse eventualmente en el sentido de que las actividades de una fuerza armada en período de conflicto armado, según el derecho inter- 
nacional humanitario, no deben considerarse actividades terroristas. Por ello, expresaba sus dudas sobre la calificación que debe aplicarse a las actividades realizadas por la organización LTTE, que justificaron, a juicio del Consejo, los actos de la Unión adoptados entre los años 2006 y 2010, para la inclusión de esta en la lista de congelación de fondos.

No obstante, el TJUE señala que la Unión no es parte en estos convenios internacionales y que, en cualquier caso, los citados convenios no se oponen a que las actividades de una fuerza armada en período de conflicto armado puedan constituir «actos terroristas», en el sentido de la Posición Común 2001/931 y del Reglamento 2580/2001, sin que haya indicio alguno de que esos convenios contradigan eventuales reglas de Derecho internacional consuetudinario que vinculen a la Unión. En efecto, por lo que respecta, en primer lugar, al derecho internacional humanitario, observa que el art. 33 del Cuarto Convenio de Ginebra prevé la prohibición de toda medida de intimidación o terrorismo. Asimismo, el art. 51, apdo. 2, del Protocolo I y el art. 13, apdo. 2, del Protocolo II establecen que quedan prohibidos los actos o amenazas de violencia cuya finalidad principal sea aterrorizar a la población civil. Por otro lado, el art. 4, apdo. 2, del Protocolo II dispone que quedarán prohibidos en todo tiempo y lugar los actos terroristas con respecto a las personas que no participen directamente en las hostilidades o que hayan dejado de participar en ellas. Además, destaca que el derecho internacional humanitario persigue objetivos distintos a los de la Posición Común 2001/931 y del Reglamento 2580/2001 y establece mecanismos diferentes. Por añadidura, las normas previstas por el derecho internacional humanitario no prohíben la adopción, fuera del marco definido por ese derecho, de medidas preventivas como aquellas de las que es objeto la organización LTTE.

En lo que atañe al derecho internacional en materia de terrorismo, observa que el art. 2, apdo. 1, letra b) del Convenio Internacional para la Represión de la Financiación del Terrorismo prevé la tipificación de «cualquier [...] acto destinado a causar la muerte o lesiones corporales graves a un civil o a cualquier otra persona que no participe directamente en las hostilidades en una situación de conflicto armado, cuando el propósito de dicho acto, por su naturaleza o contexto, sea intimidar a una población u obligar a un gobierno o a una organización internacional a realizar un acto o a abstenerse de hacerlo». El art. 8, apdo. 1, de este convenio prevé, además, la obligación de adoptar medidas de congelación de los fondos utilizados para cometer los delitos indicados en su art. 2 y no prohíbe la aplicación de medidas de congelación de fondos relativas a otros delitos terroristas. Asimismo, señala que a tenor del último considerando del Convenio Internacional para la Represión de los Atentados Terroristas Cometidos con Bombas, la exclusión del ámbito de aplicación de este convenio de las actividades de las fuerzas armadas en período de conflicto 
armado «no condona ni legitima de manera alguna actos ilícitos, ni obsta para su enjuiciamiento en virtud de otras leyes». De ello se deduce que la circunstancia de que tales actividades no estén incluidas en el ámbito de aplicación de ese convenio no excluye, no obstante, que puedan considerarse actividades ilícitas contra las que pueden emprenderse acciones judiciales, como «actos terroristas», en el sentido de la Posición Común 2001/931 y del Reglamento $2580 / 2001$. Por último, si bien algunos convenios internacionales a los que hace referencia el tribunal remitente excluyen de su ámbito de aplicación las actividades de las fuerzas armadas en período de conflicto armado, en el sentido del derecho internacional humanitario, no prohíben a los Estados partes calificar de «actos terroristas» algunas de estas actividades, o prevenir la comisión de tales actos.

Por todo ello interpreta la Posición Común 2001/931 y el Reglamento 2580/2001 en el sentido de que las actividades de una fuerza armada en período de conflicto armado, en el sentido del derecho internacional humanitario, pueden constituir «actos terroristas», conforme a dichos actos de la Unión.

\section{La Unión puede celebrar por sí sola el Tratado de Marrakech para fa- cilitar el acceso a las obras publicadas a las personas con discapacidad visual, pues este tratado puede afectar a normas comunes de la Unión Europea relativas a la protección del derecho de autor (Dictamen 3/15, de 14 de febrero de 2017, EU:C:2017:114).}

El Tratado de Marrakech (TM) para facilitar el acceso a las obras publicadas a las personas ciegas, con discapacidad visual o con otras dificultades para acceder al texto impreso impone a los Estados contratantes la obligación de establecer en su legislación nacional que determinadas entidades (a saber, establecimientos públicos y organizaciones sin ánimo de lucro que proporcionen servicios de educación, formación pedagógica, lectura adaptada o acceso a la información) puedan, sin autorización del titular del derecho de autor, reproducir o distribuir ejemplares de obras publicadas en un formato que resulte accesible a las personas ciegas, con discapacidad visual o con otras dificultades para acceder al texto impreso (en lo sucesivo, «beneficiarios»). Los Estados deben facilitar igualmente el intercambio transfronterizo de ejemplares en formato accesible mediante la autorización de determinadas formas de exportación e importación de estos ejemplares.

Al considerar que la Unión podía celebrar por sí sola (sin la participación de los Estados miembros) el TM, la Comisión presentó una propuesta de decisión de celebración del Tratado que el Consejo no adoptó. La Comisión presentó entonces ante el TJUE una solicitud de dictamen para saber si la 
Unión puede celebrar por sí sola el TM o bien si a tal efecto es necesaria la participación de los Estados miembros.

En su dictamen, el TJUE examina primero si el TM tiene relación con la política comercial común, que, en virtud del Tratado FUE, es competencia exclusiva de la Unión (art. 3, apdo. 1, TFUE). El TJUE declara que el TM no está comprendido en el ámbito de la política comercial común. En efecto, por una parte, el TM no tiene como finalidad promover, facilitar o regular el comercio internacional de ejemplares en formato accesible, sino mejorar la situación de los beneficiarios facilitando mediante diversos medios el acceso a las obras publicadas a estas personas. Por otra parte, los intercambios transfronterizos de ejemplares en formato accesible, contemplados por el TM, no pueden asimilarse a intercambios internacionales efectuados por operadores ordinarios con fines comerciales. Los intercambios solo se realizan entre establecimientos públicos u organizaciones sin ánimo de lucro en las condiciones que precisa el TM y las exportaciones e importaciones están destinadas únicamente a los beneficiarios.

El TJUE recuerda seguidamente que la Unión también tiene competencia exclusiva cuando la celebración de un acuerdo internacional puede afectar a «normas comunes» o alterar su alcance. A este respecto, el TJUE señala que la Directiva 2001/29/CE del Parlamento Europeo y del Consejo, relativa a la armonización de determinados aspectos de los derechos de autor y derechos afines a los derechos de autor en la sociedad de la información permite a los Estados miembros que lo deseen establecer una excepción o limitación a los derechos de reproducción y de comunicación al público en beneficio de personas con minusvalías. De ello se desprende que la excepción o limitación prevista por el TM deberá aplicarse en el marco del ámbito armonizado por la Directiva. Lo mismo ocurre con los regímenes de exportación e importación establecidos por este tratado, en la medida en que tienen por objeto autorizar la comunicación al público o la distribución, en el territorio de un Estado contratante, de ejemplares en formato accesible publicados en otro Estado contratante, sin obtener el consentimiento de los titulares de los derechos. En este contexto, el TJUE subraya que, aunque los Estados miembros disponen, en virtud de la Directiva, de la facultad de establecer tal excepción o limitación, se trata de una facultad concedida por el legislador de la Unión que se encuentra delimitada de forma estricta por diversas exigencias del derecho de la Unión.

El TJUE señala también que, al contrario que la Directiva, el TM establece una obligación (y no una simple facultad) de introducir una excepción o limitación en beneficio de determinadas personas con minusvalías. Por tanto, el TJUE estima que, tras la celebración del TM, todos los Estados miembros 
tendrán la obligación de establecer la excepción o limitación en favor de las personas con minusvalías.

De ello resulta que el conjunto de las obligaciones previstas por el TM están comprendidas en un ámbito ya cubierto en gran medida por "normas comunes de la Unión" y que la celebración de este Tratado puede afectar a estas normas o alterar su alcance. Dado que la celebración del TM puede afectar a la Directiva sobre los derechos de autor o alterar su alcance, el TJUE concluye que la Unión dispone de competencia exclusiva. 